\title{
Transport genes and chemotaxis in Laribacter hongkongensis: a genome-wide analysis
}

\author{
Susanna KP Lau ${ }^{1,2,3,4^{*}{ }^{\dagger}}$, Rachel YY Fan ${ }^{4 \dagger}$, Gilman KM Wong ${ }^{4 \dagger}$, Jade LL Teng ${ }^{4}$, Kong-Hung Sze ${ }^{5}$, Herman Tse ${ }^{1,2,3,4}$, \\ Kwok-Yung Yuen ${ }^{1,2,3,4}$ and Patrick CY Woo $0^{1,2,3,4^{*}}$
}

\begin{abstract}
Background: Laribacter hongkongensis is a Gram-negative, sea gull-shaped rod associated with communityacquired gastroenteritis. The bacterium has been found in diverse freshwater environments including fish, frogs and drinking water reservoirs. Using the complete genome sequence data of L. hongkongensis, we performed a comprehensive analysis of putative transport-related genes and genes related to chemotaxis, motility and quorum sensing, which may help the bacterium adapt to the changing environments and combat harmful substances.

Results: A genome-wide analysis using Transport Classification Database TCDB, similarity and keyword searches revealed the presence of a large diversity of transporters $(n=457)$ and genes related to chemotaxis $(n=52)$ and flagellar biosynthesis $(n=40)$ in the L. hongkongensis genome. The transporters included those from all seven major transporter categories, which may allow the uptake of essential nutrients or ions, and extrusion of metabolic end products and hazardous substances. L. hongkongensis is unique among closely related members of Neisseriaceae family in possessing higher number of proteins related to transport of ammonium, urea and dicarboxylate, which may reflect the importance of nitrogen and dicarboxylate metabolism in this assacharolytic bacterium. Structural modeling of two $C^{4}$-dicarboxylate transporters showed that they possessed similar structures to the determined structures of other DctP-TRAP transporters, with one having an unusual disulfide bond. Diverse mechanisms for iron transport, including hemin transporters for iron acquisition from host proteins, were also identified. In addition to the chemotaxis and flagella-related genes, the L. hongkongensis genome also contained two copies of qseB/qseC homologues of the Al-3 quorum sensing system.

Conclusions: The large number of diverse transporters and genes involved in chemotaxis, motility and quorum sensing suggested that the bacterium may utilize a complex system to adapt to different environments. Structural modeling will provide useful insights on the transporters in L. hongkongensis.
\end{abstract}

\section{Background}

Laribacter hongkongensis is a Gram-negative, sea gullshaped, rod that belongs to the Neisseriaceae family of $\beta$-proteobacteria [1,2]. The bacterium was first isolated from the blood and empyema pus of a man with alcoholic cirrhosis and bacteremic empyema thoracis in Hong Kong [1]. Using the selective medium, cefoperazone MacConkey agar, the bacterium was subsequently isolated from the stool of patients with gastroenteritis $[3,4]$. In a multicenter case-control study, L. hongkongensis was shown to be associated with community-acquired

\footnotetext{
* Correspondence: skplau@hkucc.hku.hk; pcywoo@hkucc.hku.hk

† Contributed equally

'State Key Laboratory of Emerging Infectious Diseases, Hong Kong

Full list of author information is available at the end of the article
}

gastroenteritis, with recent travel and eating fish being risk factors [5]. Apart from the human gut, L. hongkongensis has also been isolated from gut of freshwater animals including fish and Chinese tiger frogs as well as water from drinking water reservoirs [2,5-9]. In order to adapt to the changing environments and intestines of different animal hosts including human, fish and amphibians, L. hongkongensis must possess mechanisms to combat harmful substances in the environment and immune defense of animal hosts.

Transport-related proteins of bacteria are important in allowing the uptake of essential nutrients or ions, and extrusion of metabolic end products and hazardous substances. Bacteria employ different mechanisms for transport of different chemicals and these mechanisms have

\section{Biomed Central}


been classified into seven major categories according to the Transport Protein Database (TCDB): channels and pores (class 1), electrochemical potential-driven transporters (class 2), primary active transporters (class 3), group translocators (class 4), transmembrane electron carriers (class 5), accessory factors involved in transport (class 8), and incompletely characterized transport systems (class 9).

Bacteria also possess sophisticated signaling systems to sense and adapt to various substances in the environment. Depending on whether the environmental substances are attractants or repellents, the bacterium may migrate towards or away from the substances, which include certain amino acids, sugars, and metal ions [10-12]. This sense-and-swim ability is important for bacteria to be able to find the suitable environment for optimal growth. Chemotaxis involves two separate systems, the chemoreceptors located in the bacterial cell membrane which are important for sensing the binding compounds, and the transduction proteins which are involved in the downstream signal transduction in response to the stimuli. The chemoreceptors are also called methyl-accepting chemotaxis proteins (MCPs), which are reversibly methylated and function as homodimers [11,13].

The availability of the complete genome sequence of L. hongkongensis has allowed an opportunity to study its biology and important factors for adaptation to the changing environment [14]. We have previously found that transport-related proteins, including all seven major categories of transporters, account for about $14.1 \%$ of all coding sequences in the L. hongkongensis genome, suggesting that this group of proteins may be important for survival of the bacterium in the various environments and hosts [14]. Genes related to motility and chemotaxis were also identified [14]. Except for the first strain isolated from blood culture and empyema pus of a patient which was likely a non-motile variant, all strains from patients with gastroenteritis, animals or environmental water samples are motile with polar flagellae $[1,4-7,10]$, suggesting that chemotaxis and motility may be an important mechanism for environmental adaptation in most isolates of L. hongkongensis. In this study, a comprehensive analysis of putative transport-related genes and genes related to chemotaxis, motility and quorum sensing in the L. hongkongensis genome is performed.

\section{Results and discussion}

\section{Transport genes in L. hongkongensis genome}

A huge diversity of transporters, including those from all seven major categories, were identified in the L. hongkongensis genome, as described in our previous complete genome report [14]. This may reflect its ability to adapt to various environments, including freshwater animals, water and human intestines. These transporters included: (1) 48 channels and pores, (2) 134 electrochemical potentialdriven transporters, (3) 194 primary active transporters, (4) 9 group translocators, (5) 16 transmembrane electron carriers, (6) 7 accessory factors involved in transport and (7) 49 transporters of incompletely characterized transport systems (Table 1).

\section{Channels and pores}

The outer membranes of lipid bilayer envelopes of Gram-negative bacteria contain large numbers of waterfilled transmembrane protein channels known as porins [15]. They serve as a molecular filter allowing for permeation of hydrophilic molecules up to a certain size or specific solutes into the periplasmic space. Some bacterial porins also serve as receptor for phage and bacteriocin binding [16]. X-ray crystoallography studies and atomic structures have revealed that porin molecules exists as trimers, with the transmembrane core composed of mostly $\beta$-sheets and some $\alpha$-helixes [15]. The L. hongkongensis genome contained 48 coding sequences (CDSs) belonging to channels and pores, of which 17 were $\alpha$-type channels, 29 were $\beta$-barrel porins and 2 were holins (Table 1).

Among the $17 \alpha$-type channels, five were mechanosensitive channels, including one large conductance mechanosensitive channel (LHK_02562) and four small conductance mechanosensitive channels (LHK_01830, LHK_01942, LHK_02394 and LHK_02965), which are responsible for mediating resistance to mechanophysical changes [17]. Interestingly, three CDSs encoding proteins of the ammonium transporter family were identified in the L. hongkongensis genome, as compared to only one copy such genes in Chromobacterium violaceum, the most closely related bacterial species of the Neisseriaceae family with complete genome sequence available (Table 2). Moreover, a homologue of urea transporter responsible for urea uptake (LHK_01044) was also present in L. hongkongensis (Table 2), while this protein was absent in C. violaceum and the pathogenic Neisseria spp., Neisseria gonorrhoeae and Neisseria meningitidis. This may reflect the importance of nitrogen metabolism of the bacterium, as L. hongkongensis is assacharolytic and has been shown to use different pathways for arginine synthesis regulated at different temperatures [14]. In fact, the habitats of the closely related bacterial species are quite different from that of L. hongkongensis, where the latter can survive in human intestine in addition to diverse freshwater environment. This may also explain its unique ability in maximizing nitrogen metabolism. Among the $\beta$-barrel porins, the OmpA-OmpF-type porins are most well known in bacteria to allow passive diffusion of hydrophilic substrates across the outer membrane. Three CDSs coding for putative OmpA-OmpF-type porins were identified in the L. hongkongensis genome. Interestingly, two homologues of another $\beta$-barrel porin, fatty acid transporter gene 
Table 1 Transporters in L. hongkongensis and C. violaceum

\begin{tabular}{|c|c|c|c|c|c|c|}
\hline \multirow[t]{2}{*}{ Category } & \multicolumn{3}{|c|}{ L. hongkongensis } & \multicolumn{3}{|c|}{ C. violaceum } \\
\hline & $\begin{array}{l}\text { No. of } \\
\text { CDSs }\end{array}$ & $\begin{array}{l}\% \text { of total } \\
\text { CDSs }\end{array}$ & $\begin{array}{l}\% \text { of transport } \\
\text { CDSs }\end{array}$ & $\begin{array}{l}\text { No. of } \\
\text { CDSs }\end{array}$ & $\begin{array}{l}\% \text { of total } \\
\text { CDSs }\end{array}$ & $\begin{array}{l}\% \text { of transport } \\
\text { CDSs }\end{array}$ \\
\hline Channel and Pores & 48 & 1.5 & 10.5 & 63 & 1.4 & 11.3 \\
\hline$\alpha$-type channels & 17 & & & 26 & & \\
\hline$\beta$-barrel porins & 29 & & & 43 & & \\
\hline Pore-forming toxins (proteins and peptides) & 0 & & & 3 & & \\
\hline Holins & 2 & & & 2 & & \\
\hline Electrochemical Potential-driven Transporters & 134 & 4.1 & 29.3 & 161 & 3.7 & 28.8 \\
\hline Porters (uniporters, symporters and antiporters) & 132 & & & 159 & & \\
\hline Ion-gradient-driven energizers & 2 & & & 2 & & \\
\hline Primary Active Transporters & 194 & 6.0 & 42.5 & 252 & 5.7 & 45.0 \\
\hline P-P-bond-hydrolysis-driven transporters & 150 & & & 206 & & \\
\hline Decarboxylation-driven transporters & 5 & & & 7 & & \\
\hline Oxidoreduction-driven transporters & 39 & & & 39 & & \\
\hline Group Translocators & 9 & 0.3 & 2.0 & 18 & 0.4 & 3.2 \\
\hline Phosphotransfer-driven group translocators & 2 & & & 8 & & \\
\hline Acyl CoA ligase-coupled transporters & 7 & & & 10 & & \\
\hline Transmembrane Electron Carriers & 16 & 0.5 & 3.5 & 13 & 0.3 & 2.3 \\
\hline Transmembrane 2-electron transfer carriers & 14 & & & 12 & & \\
\hline Transmembrane 1-electron transfer carriers & 2 & & & 1 & & \\
\hline Accessory Factors Involved in Transport & 7 & 0.2 & 1.5 & 20 & 0.5 & 3.6 \\
\hline Auxiliary transport proteins & 7 & & & 20 & & \\
\hline Incompletely Characterized Transport Systems & 49 & 1.5 & 10.7 & 33 & 0.7 & 5.9 \\
\hline $\begin{array}{l}\text { Recognized transporters of unknown } \\
\text { biochemical mechanism }\end{array}$ & 15 & & & 14 & & \\
\hline Putative transport proteins & 34 & & & 19 & & \\
\hline
\end{tabular}

Table $2 \alpha$-type channels in $L$. hongkongensis and their closest homologues

\begin{tabular}{|c|c|c|c|c|}
\hline CDS & Protein & Closest match organism & $\begin{array}{l}\text { Best E- } \\
\text { value }\end{array}$ & $\begin{array}{l}\text { Amino acid identity } \\
(\%)\end{array}$ \\
\hline LHK_02933 & Ammonium transporter & L. nitroferrum & $2.00 \mathrm{E}-146$ & 73.18 \\
\hline LHK_03249 & Ammonium transporter & Shewanella halifaxensis & $2.00 \mathrm{E}-118$ & 62.32 \\
\hline LHK_03154 & Ammonium transporter family protein & L. nitroferrum & $1.00 \mathrm{E}-163$ & 78.99 \\
\hline LHK_02207 & Flagellar motor protein MotA & L. nitroferrum & $1.00 \mathrm{E}-122$ & 74.48 \\
\hline LHK_00970 & Ion transporter & C. violaceum & $5.00 \mathrm{E}-78$ & 58.96 \\
\hline LHK_02562 & Large-conductance mechanosensitive channel & Pelodictyon luteolum & $2.00 \mathrm{E}-43$ & 56.95 \\
\hline LHK_01830 & Transmembrane protein & C. violaceum & 2.00E-109 & 57.52 \\
\hline LHK_01942 & Mechanosensitive ion channel protein & Janthinobacterium sp. Marseille & 5.00E-79 & 41.26 \\
\hline LHK_02394 & MscS Mechanosensitive ion channel & L. nitroferrum & $7.00 \mathrm{E}-55$ & 48.95 \\
\hline LHK_02965 & $\begin{array}{l}\text { Transporter, small conductance mechanosensitive ion channel } \\
\text { family }\end{array}$ & E. coli O157:H7 & $5.00 \mathrm{E}-73$ & 61.04 \\
\hline LHK_02739 & Molecular chaperone DnaK & C. violaceum & 0 & 85.98 \\
\hline LHK_02206 & OmpA/MotB domain protein & L. nitroferrum & 4.00E-97 & 75.46 \\
\hline LHK_01044 & Urea transporter & $\begin{array}{l}\text { Methylobacterium extorquens } \\
\text { PA1 }\end{array}$ & $1.00 \mathrm{E}-65$ & 50.46 \\
\hline LHK_00053 & TolQ-related transport transmembrane protein & C. violaceum & $1.00 \mathrm{E}-86$ & 74.66 \\
\hline LHK_03174 & TolR protein & C. violaceum & $5.00 \mathrm{E}-30$ & 51.88 \\
\hline LHK_00499 & Probable exbB-like biopolymer transport & C. violaceum & $4.00 \mathrm{E}-55$ & 59.31 \\
\hline LHK_00498 & Biopolymer transport exbD transmembrane protein & Burkholderia pseudomallei112 & 7.00E-36 & 55.88 \\
\hline
\end{tabular}


$(f a d L)$, were also found, which may be important for uptake of long-chain fatty acids in freshwater environments poor in lipids or fatty acids.

\section{Electrochemical potential-driven transporters}

The L. hongkongensis genome possessed a large number of CDSs $(n=134)$ encoding for putative electrochemical potential-driven transporters, among which the majority (132 CDSs) were porters including uniporters, symporters and antiporters, while the remaining two CDSs were iongradient-driven energizers (Table 1). Of the 132 porters, 19 (14.3\%) belonged to the major facilitator superfamily (MFS). MFS proteins are important transporters in bacteria, which allow transport of molecules by an electrochemical ion gradient and typically contain a single subunit with 12 membrane-spanning helixes [18]. The MFS proteins of L. hongkongensis were predicted to mediate transport of diverse substrates including ions, drugs and metabolites. Another major family of porters were the resistance-nodulation-cell division (RND) superfamily (28 CDSs), which are responsible for transporting a wide variety of substrates including antibiotics, dyes, detergents, fatty acids, bile salts, organic solvents, heavy metals, autoinducers and lipooligosaccharides in Gram-negative bacteria $[19,20]$. Other porters belonged to diverse families of proteins which facilitate the transport of diverse substances including ions, amino acids, drugs, heavy metal such as nickel and cobalt, nucleobase, $\mathrm{C}_{4}$-dicarboxylates and other metabolites. The presence of various porters may be involved in acquisition of essential substances for metabolism and bacterial resistance to environmental toxic substances including heavy metals. Interestingly, a total of 11 porters for dicarboxylate transport were found in L. hongkongensis genome, as compared to only 6 in $C$. violaceum and 1 each in $N$. meningitidis and $N$. gonorrhoeae genomes (Table 3 ). $\mathrm{C}_{4}$-dicarboxylates are intermediates in TCA cycle that can be utilized by bacteria as nonfermentable carbon and/or energy sources under aerobic or anaerobic conditions [21]. Some $\mathrm{C}_{4}$-dicarboxylates, such as succinate, oxalate and malate, can also be found in nature [22]. The presence of high number of $\mathrm{C}_{4}$-dicarboxylates transporters may reflect the ability of using $\mathrm{C}_{4}$-dicarboxylates as carbon sources in L. hongkongensis, as the bacterium is assacharolytic, lacking a complete glycolytic pathway, and is in line with our experiments showing that L-malate can be used as its sole carbon source [14].

Six of the 11 porters for dicarboxylate transport found in L. hongkongensis genome were believed to form two DctPtype tripartite ATP-independent periplasmic (TRAP) transporters which belong a heterogeneous group of substrate-binding protein (SBP)-dependent secondary transporters of a diverse range of substrates found in bacteria and archaea [23-25]. The genes encoding the 3 subunits were arranged in an operon, with two membrane proteins DctQ and DctM associating with DctP to form a $\mathrm{C}_{4}$-dicarboxylate TRAP transporter [26]. Several TRAP transporters have been characterized in detail, with the structures of at least seven DctP-type SBP subunits determined [25]. These studies revealed significant structural and architectural similarities among the different SBPs, while highlighting the differences that permitted these proteins to bind their respective substrates with high affinity and specificity. Besides substrate recognition, it was also found that the SBP performs other essential functions [27], and likely interacts with the integral membrane components in a hitherto undiscovered manner. One operon (LHK_00983-00984-00985), encoding $\mathrm{C}_{4}$-dicarboxylate transporter, was found downstream of several genes related to allantoin regulation and utilization; while the other operon (LHK_01394-01393-01392) was located upstream of the maeB gene encoding NADP-dependent malate dehydrogenase. The SBP encoded by LHK_00983 (DctP_00983) was a 331 aa protein containing a 22 aa Nterminal signal peptide, with a predicted molecular weight of $33.9 \mathrm{kDa}$. It possessed $48 \%$ amino acid identity to the closest homolog in Roseovarius sp. TM1035 (NCBI accession no.: ZP_01881277). The SBP encoded by LHK_01394 (DctP_01394) was a 335 aa protein containing a 24 aa Nterminal signal peptide, with a predicted molecular weight of $34.3 \mathrm{kDa}$. It possessed $74 \%$ amino acid identity to the closest homolog in C. violaceum ATCC12472. The homology model and structural alignment of the homology model showed that the overall structure of DctP_00983 and DctP_01394 was very similar to the determined structures of other DctP-type SBPs (Figure 1 and 2, and see Supplementary material). Similar to other DctP homologs, they were divided into two domains with conserved arrangements of $\alpha$-helices and $\beta$-sheets, which are

Table 3 Porters for dicarboxylates in L. hongkongensis and related bacteria

\begin{tabular}{|c|c|c|c|c|}
\hline Family & L. hongkongensis & C. violaceum & N. meningitidis & N. gonorrhoeae \\
\hline C4-Dicarboxylate Uptake (Dcu) Family & 0 & 2 & 0 & 0 \\
\hline Dicarboxylate/Amino Acid:Cation (Na or H) Symporter (DAACS) Family & 3 & 1 & 0 & 0 \\
\hline Tripartite ATP-independent Periplasmic Transporter (TRAP-T) Family & 6 & 3 & 0 & 0 \\
\hline Divalent Anion:Na+ Symporter (DASS) Family & 1 & 0 & 1 & 1 \\
\hline $\mathrm{C}_{4}$-dicarboxylate Uptake C (DcuC) Family & 1 & 0 & 0 & 0 \\
\hline Total & 11 & 6 & 1 & 1 \\
\hline
\end{tabular}




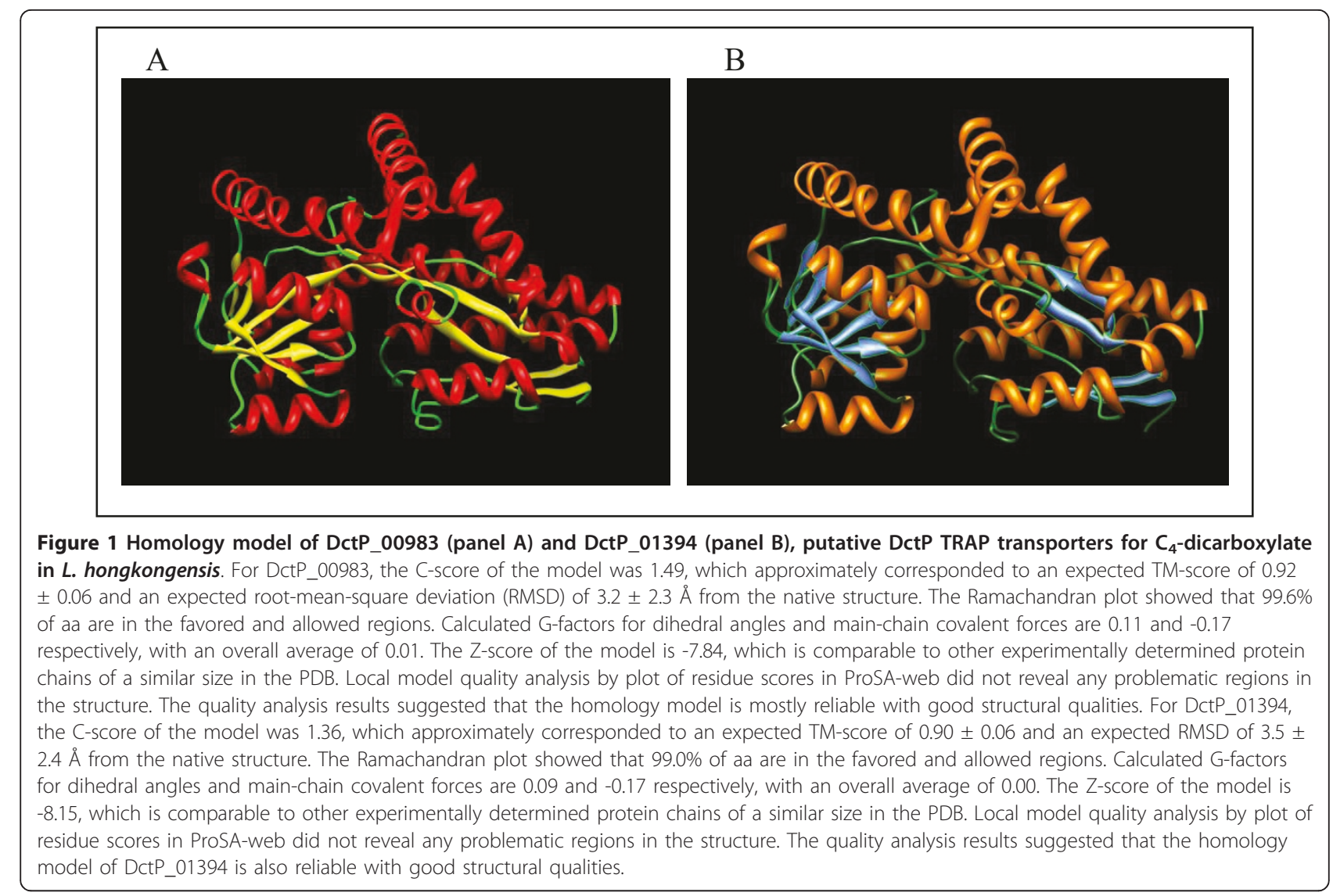

connected by a characteristic hinge made up of two $\beta$ strands and an $\alpha$-helix. A highly conserved arginine residue in domain II is present in both proteins (Arg145 of DctP_00983 and Arg147 of DctP_01394), which corresponds to Arg147 in SiaP of H. influenzae essential to SBP function by forming a salt bridge with the carboxylate group of the ligand [28]. Interestingly, a disulfide bond was predicted between the cysteine residues at positions
A

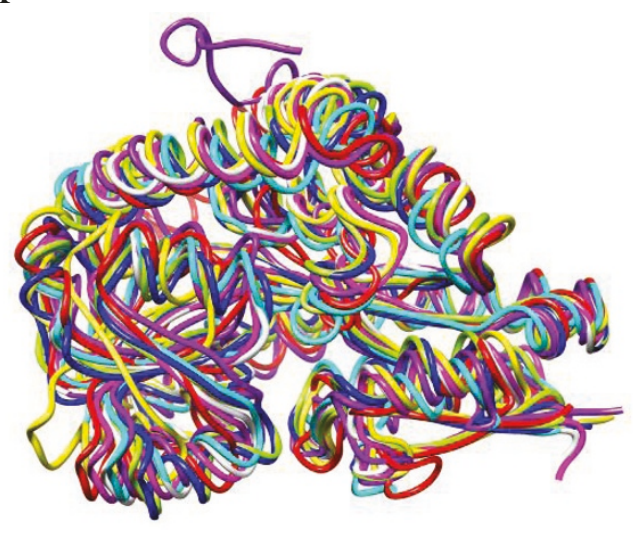

$\mathrm{B}$

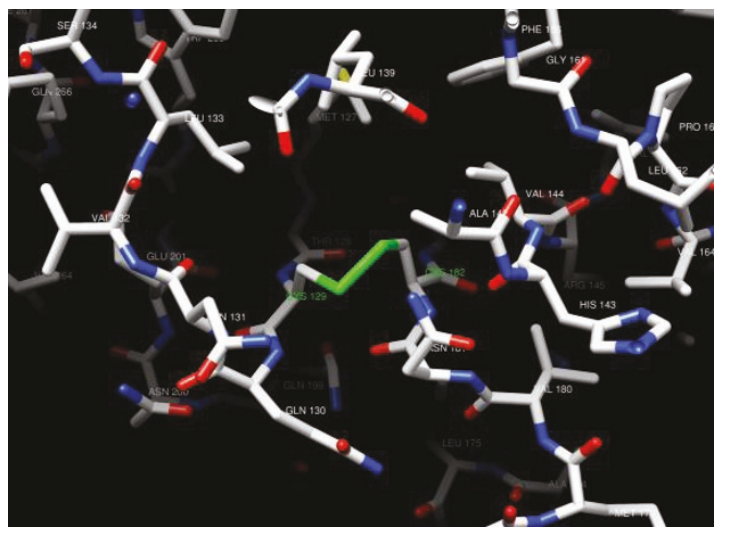

Figure 2 Structural alignment of the homology model of DctP_00983 and DctP_01394, showing similar structures to other DctP-type SBPs (panel A) and a disulfide bond predicted between the cysteine residues at positions 129 and 182 of DctP_00983 (panel B). RMSD between DctP_00983 and the related structures ranged from 0.761 to $1.290 \AA \AA$. RMSD between DctP_01394 and the related structures ranged from 0.891 to $1.377 \AA$. 
129 and 182 for DctP_00983 (Figure 2) by homology modeling and sequence analysis. This structural feature was also found in the closest homolog in Roseovarius sp. TM1035, but absent from other related DctP-type SBP homologs including DctP_01394.

\section{Primary active transporters}

Primary active transporters mediate energy-driven transport of substances in and out of bacterial cells by using ATP hydrolysis, photon absorption, electron flow, substrate decarboxylation, or methyl transfer [29]. Primary active transporters were the most abundant class of transporters (194 CDSs), constituting 6\% of CDSs in the L. hongkongensis genome, among which 150 belonged to P-P-bond-hydrolysis-driven transporters (Table 1). Of the $150 \mathrm{P}$-P-bond-hydrolysis-driven transporters, 109 were ATP-binding cassette $(\mathrm{ABC})$ transporters which are one of the largest groups of membrane proteins using energy from ATP hydrolysis for transport. In bacteria, they reside in the inner membrane and are involved in both uptake and export of a wide range of substances. All $\mathrm{ABC}$ transporters share a common basic structure which consists of four domains: two transmembrane domains, typically with six transmembrane spans per domain, and two cytoplasmic nucleotide-binding domains which catalyse nucleotide hydrolysis [30]. In bacteria, these domains are encoded as separate polypeptides. Determined by the structure of the transmembrane domain, ABC transporters are typically specific for the substrates that they are responsible for, although some may transport for multiple related substances. As a result, the numbers of $A B C$ transporters in different bacterial species vary widely, depending on its need for adaptation to varying environmental conditions [31]. The ABC transporters in the L. hongkongensis are likely involved in the active transport of diverse substances, including carbohydrate, amino acids or peptides, ions, vitamins, lipids, drugs and heavy metals including molybdenum, iron, zinc, cobalt, magnesium, copper, cadmium, mercury, lead, arsenite and nickel. These systems were often arranged in gene clusters comprising the ATP-binding protein and two auxiliary proteins, a permease and a substrate-binding protein. Compared to the $70 \mathrm{ABC}$ transporters found in E. coli [31], the L. hongkongensis genome contained a large number of such proteins, reflecting its ability to adapt to different hosts and environment.

Apart from P-P-bond-hydrolysis-driven transporters, other primary active transporters identified in the L. hongkongensis genome included oxidoreduction-driven transporters (39 CDSs) and decarboxylation-driven transporters (5 CDSs), which use chemical energy to perform transport of charged or uncharged molecules across the membrane against the concentration gradient [32].

\section{Group translocators}

Of the nine group translocators, two were phosphotransfer-driven group translocators and seven were acyl CoA ligase-coupled transporters belonging to the fatty acid transporter (FAT) family. The phosphotransferase group translocators are components of the bacterial phosphotransferase system (PTS), which catalyzes translocation of sugars and hexitols with concomitant phosporylation, and regulates the metabolism in response to the availability of carbohydrates. PTSs consist of two cytoplasmic proteins, enzyme I (EI) and HPr, and a variable number of sugarspecific transport complexes (Enzymes II ${ }^{\text {sugar }}$ ) belonging to the group translocators. While the Escherichia coli genome encoded 38 different PTS proteins, the L. hongkongensis genome encoded only one gene for EI and HPr each and two genes for transporters, one containing protein-N pphosphohistidine-sugar phosphotransferase IIA domain and the other containing nitrogen-regulatory fructosespecific IIA domain [33]. This is likely related to the relative unimportance of sugar metabolism in L. hongkongensis.

\section{Transmembrane electron carriers}

There were 16 transmembrane electron carriers in the L. hongkongensis genome, including 14 transmembrane 2 - and two transmembrane 1-electron transfer carriers. Among the 14 transmembrane 2-electron transfer carriers, 12 belonged to the prokaryotic molybdopterin-containing oxidoreductase (PMO) family, and the other 2 belonged to the disulfide bond oxidoreductase $\mathrm{D}$ (DsbD) and $\mathrm{B}$ (DsbB) family respectively.

\section{Accessory factors involved in transport}

There were seven accessory factors belonging to auxiliary transport proteins in the L. hongkongensis genome, 3 belonging to the membrane fusion protein (MFP) family, 2 to the phosphotransferase system enzyme I (EI) family, 1 to the phosphotransferase system $\mathrm{HPr}(\mathrm{HPr})$ family and 1 to the stomatin/podocin/band $7 /$ nephrosis.2/ SPFH (stomatin) family.

\section{Incompletely characterized transport systems}

Of the 49 CDSs belonging to incompletely characterized transport system, 15 were recognized transporters of unknown biochemical mechanism, with 6 belonging to the putative type VI symbiosis/virulence secretory pathway (VISP) family, 2 to the HlyC/CorC (HCC) family, 2 to the capsular polysaccharide exporter (CPS-E) family, 1 to the tellurium ion resistance (TerC) family and the remaining 4 being metal ion transporters. The other $34 \mathrm{CDSs}$ were putative transport proteins, including 2 CDSs of the camphor resistance $(\mathrm{CrcB})$ family and 1 probable hemolysin III.

\section{Iron Transport in L. hongkongensis}

Iron is an essential metal for most microorganisms used in many key molecules involved in metabolism. In bacteria, 
iron metabolism has been shown to be important in adaptation to the environment especially within the host and as a result related to virulence. Diverse mechanisms for iron transport were identified in the L. hongkongensis genome, suggesting that the bacterium is able to adapt to iron limitation present in human body which represents one of the non-specific immune response called induced hypoferremia [34,35]

\section{Siderophores and iron uptake}

Siderophores are low molecular mass compounds with high affinity for ferric iron. In contrast to C. violaceum which produced siderophores for iron acquisition, proteins related to siderophore production were not found in L. hongkongensis genome. However, a homolog of TonB-dependent siderophore receptor (LHK_00497) was present, as described in our previous report [14]. Although Listeria monocytogenes also did not produce siderophores for iron acquisition, it was able to obtain iron by using either exogenous siderophores produced by various microorganisms or natural catechol compounds widespread in the environment [36,37]. It remains to be determined if L. hongkongensis can utilize exogenous siderophores or other natural iron-binding compounds for iron acquisition.

\section{Hemin transport}

Despite the inability to produce siderophores, a set of genes related to the transport of hemin were identified in L. hongkongensis genome (8 CDSs compared to 6 CDSs in C. violaceum). The $8 \mathrm{CDSs}$ included TonB-dependent receptor (LHK_01193), hemin degrading factor (LHK_ 01192), ABC transporter permease (LHK_01189), ferric citrate transport system ATP-binding protein (LHK_ 01188), hemin-binding periplasmic protein (LHK_01190), hemin importer ATP-binding subunit (LHK_01427), hemin ABC transporter permease protein (LHK_01428) and Fur family ferric uptake regulator (LHK_01431). The conserved domains for hemin receptor, FRAP and NPNL, were also identified in the TonB-dependent receptor [38]. This suggests that L. hongkongensis is able to utilize iron source form host proteins, which may be important for survival in its hosts. Three other CDSs, homologous to $f b p A$ (LHK_02634), $f b p B$ (LHK_02635) and ATP-binding protein (LHK_02636), ABC transporters for transferrin and lactoferrin, were also present, although the outer membrane receptor is not found.

\section{$A B C$ transporters of the metal type}

A cluster of three genes encoding an $\mathrm{ABC}$ transporter of the metal type (homologous to that identified in C. violaceum) was identified in the L. hongkongensis genome. They encoded a periplasmic $\mathrm{Mn}^{2+} / \mathrm{Zn}^{2+}$-binding (lipo)pro-

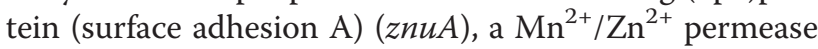
component $(z n u B)$ and the ATPase component $(z n u C)$. In addition, a gene encoding a putative cadmium-translocating ATPase component (cadmium-translocating P-type
ATPase) (CadA) (LHK_00449) was also present. A similar gene was also found in C. violaceum (CV1154), which was thought to be a surface adhesion A component for $\mathrm{Mn}^{2}$ ${ }^{+} / \mathrm{Zn}^{2+}$ binding. The Fur family ferric uptake regulator (zur) (LHK_01344) was also present.

\section{Other transporters}

In addition to the above transporters, two CDSs encoding ferrous iron transport proteins, feoA (LHK_03044) and feoB (LHK_03045), were identified in L. hongkongensis genome, which are believed to provide iron supply under anaerobic or low $\mathrm{pH}$ conditions in bacteria [39]. Three other CDSs homologous to iron uptake $\mathrm{ABC}$ transporter periplasmic solute-binding protein (LHK_01590), ABC transporter permease (LHK_01593) and ABC transporter ATP-binding protein (LHK_01591) were also found.

\section{Iron storage}

Mechanism required for storage of iron after its acquisition from the environment was present in L. hongkongensis, which mainly depends on two proteins: bacterioferritin (BFR) (LHK_01239, homologous to CV3399 in C. violaceum) and frataxin-like homolog (LHK_00023, homologous to Daro_0208 in Dechloromonas aromatica). The BFR is an iron-storage protein with close similarity to the ferritins found in both eukaryotes and prokaryotes [40]. The frataxin-like homolog has been implicated in iron storage in other bacteria. The frataxin-like domain is related to frataxin, the protein mutated in Friedreich's ataxia which is therefore proposed to result from decreased mitochondrial iron storage $[41,42]$.

\section{Regulation of iron transport}

Fur protein is a global repressor protein by forming Fur$\mathrm{Fe}^{2+}$ complexes that bind to iron-dependent promoter during iron-rich conditions. It regulates ferrichrome (fhuABCDG), ferric citrate (fecABCDE) and ferrous iron $(f e o A B C)$ uptake systems. The Fur protein in L. hongkongensis was encoded in CDS LHK_01431 (homologous to FuraDRAFT_2340 in Lutiella nitroferrum).

\section{Chemotaxis in L. hongkongensis \\ Methyl-accepting chemotaxis and chemosensory transducer proteins}

A total of 52 open reading frames (CDSs) were related to chemotaxis, of which 29 encoded MCPs and 22 were chemosensory transducer proteins. Most genes encoding MCPs were scattered throughout the L. hongkongensis genome, while the genes encoding transducer proteins were mostly arranged in three gene clusters as described in our previous report (Table 4) [14].

All the predicted MCPs in L. hongkongensis possessed a transmembrane domain, which is compatible with their anticipated location in the bacterial cell membrane and function as receptors. Conserved domain structures were also identified in some of the MCPs. The plasmid 
Table 4 CDSs related to chemotaxis in L. hongkongensis genome

\begin{tabular}{|c|c|c|c|c|c|c|}
\hline CDS & Gene & Product & $\begin{array}{l}\text { Organism with the } \\
\text { closest matching } \\
\text { sequences }\end{array}$ & E-value & Identities & Cluster $^{a}$ \\
\hline LHK_00115 & & histidine kinase, HAMP region: chemotaxis sensory transducer & D. aromatica & $1 e-96$ & $242 / 680(35 \%)$ & \\
\hline LHK_00482 & & methyl-accepting chemotaxis sensory transducer & L. nitroferrum & $4 \mathrm{e}-55$ & 164/543(30\%) & \\
\hline LHK_00516 & & methyl-accepting chemotaxis sensory transducer & L. nitroferrum & $8 e-129$ & $265 / 513(51 \%)$ & \\
\hline LHK_00553 & & diguanylate phosphodiesterase & C. violaceum & $6 e-111$ & $211 / 406(51 \%)$ & CA \\
\hline LHK_00554 & cheAl & CheA signal transduction histidine kinase & L. nitroferrum & 0 & $443 / 613(72 \%)$ & CA \\
\hline LHK_00555 & chez1 & chemotaxis phosphatase, Chez & L. nitroferrum & $2 e-69$ & 139/244(59\%) & CA \\
\hline LHK_00556 & cher1 & chemotaxis regulator protein $\mathrm{CheY}$ & C. violaceum & $4 e-61$ & 109/130 (83\%) & CA \\
\hline LHK_00557 & chev1 & chemotaxis protein $\mathrm{CheV}$ & C. violaceum & $1 e-138$ & $240 / 314(76 \%)$ & CA \\
\hline LHK_00558 & chev2 & chemotaxis protein CheV & C. violaceum & $5 e-147$ & $251 / 313(80 \%)$ & CA \\
\hline LHK_00559 & & two-component sensor histidine kinase & L. nitroferrum & $2 e-59$ & 169/381 (44\%) & CA \\
\hline LHK_00560 & & chemotaxis sensory transducer & D. aromatica & $6 e-24$ & 100/320 (31\%) & CA \\
\hline LHK_00561 & cher2 & chemotaxis protein cheY & D. aromatica & $8 e-46$ & 85/121 (70\%) & CA \\
\hline LHK_00562 & cheA2 & chemotaxis protein CheA & C. violaceum & $2 e-161$ & $358 / 746(47 \%)$ & CA \\
\hline LHK_00563 & chew & CheW protein & $\begin{array}{l}\text { Burkholderia } \\
\text { phytofirmans }\end{array}$ & $1 e-40$ & $95 / 153(62 \%)$ & CA \\
\hline LHK_00564 & & methyl-accepting chemotaxis protein & C. violaceum & $4 e-143$ & $315 / 475(66 \%)$ & CA \\
\hline LHK_00565 & cher & CheR chemotaxis protein methyltransferase & $\begin{array}{l}\text { Janthinobacterium } \\
\text { sp. Marseille }\end{array}$ & $5 e-68$ & $125 / 273(45 \%)$ & CA \\
\hline LHK_00566 & cheB1 & chemotaxis-specific methylesterase & $\begin{array}{l}\text { Nitrosomonas } \\
\text { europaea }\end{array}$ & $2 e-99$ & 186/355 (52\%) & CA \\
\hline LHK_00567 & cheD & chemoreceptor glutamine deamidase CheD & D. aromatica & $5 e-59$ & 108/189 (57\%) & CA \\
\hline LHK_00603 & & methyl-accepting chemotaxis protein & C. violaceum & $7 e-103$ & $242 / 624(38 \%)$ & \\
\hline LHK_00617 & & methyl-accepting chemotaxis protein IV & C. violaceum & $2 \mathrm{e}-100$ & $223 / 481(46 \%)$ & \\
\hline LHK_00700 & & methyl-accepting chemotaxis sensory transducer & $\begin{array}{l}\text { Allochromatium } \\
\text { vinosum }\end{array}$ & 0 & $384 / 715(53 \%)$ & \\
\hline LHK_00726 & aer1 & methyl-accepting chemotaxis sensory transducer with Pas/Pac sensor & L. nitroferrum & $7 e-114$ & $232 / 528(43 \%)$ & \\
\hline LHK_00935 & cher & MCP methyltransferase, CheR-type & L. nitroferrum & $2 \mathrm{e}-92$ & $170 / 282(60 \%)$ & \\
\hline LHK_01020 & & putative aromatic hydrocarbon chemotaxis transducer & Azoarcus sp. & $4 e-62$ & 140/338 (41\%) & \\
\hline LHK_01116 & & methyl-accepting chemotaxis protein & $\begin{array}{l}\text { Denitrovibrio } \\
\text { acetiphilus }\end{array}$ & $1 e-59$ & $152 / 461(32 \%)$ & \\
\hline LHK_01212 & & methyl-accepting chemotaxis sensory transducer & L. nitroferrum & $1 e-135$ & $261 / 476(54 \%)$ & \\
\hline LHK_01359 & cher3 & chemotaxis regulator protein $\mathrm{CheY}$ & C. violaceum & $1 e-56$ & $102 / 127(80 \%)$ & $C B$ \\
\hline LHK_01360 & chev3 & chemotaxis protein CheV & C. violaceum & $1 e-134$ & $231 / 309(74 \%)$ & $C B$ \\
\hline LHK_01361 & & methyl-accepting chemotaxis sensory transducer & L. nitroferrum & $6 e-47$ & $157 / 506(31 \%)$ & $C B$ \\
\hline LHK_01372 & & chemotaxis sensory transducer & D. aromatica & $4 e-49$ & $166 / 534(31 \%)$ & \\
\hline LHK_01470 & & putative aromatic hydrocarbon chemotaxis transducer & Azoarcus sp. & $2 e-93$ & $222 / 539(41 \%)$ & \\
\hline LHK_01602 & & methyl-accepting chemotaxis sensory transducer & L. nitroferrum & 0 & $339 / 601(56 \%)$ & \\
\hline LHK_01618 & & methyl-accepting chemotaxis sensory transducer & L. nitroferrum & $2 \mathrm{e}-87$ & 209/525 (39\%) & \\
\hline LHK_01706 & & methyl-accepting chemotaxis protein IV & C. violaceum & $1 e-121$ & $247 / 481(51 \%)$ & \\
\hline LHK_01721 & & methyl-accepting chemotaxis protein & C. violaceum & $4 e-113$ & $240 / 627(38 \%)$ & \\
\hline LHK_02037 & & methyl-accepting chemotaxis sensory transducer & $\begin{array}{l}\text { Leptospirillum } \\
\text { ferrodiazotrophum }\end{array}$ & $5 e-63$ & 137/327 (41\%) & \\
\hline LHK_02158 & aer2 & methyl-accepting chemotaxis sensory transducer with Pas/Pac sensor & Ralstonia pickettii & $6 e-39$ & $98 / 276(35 \%)$ & \\
\hline LHK_02165 & & methyl-accepting chemotaxis protein & C. violaceum & $8 e-146$ & $275 / 631(43 \%)$ & \\
\hline LHK_02364 & CheB2 & response regulator receiver modulated $C$ heB methylesterase & $\begin{array}{l}\text { Geobacter } \\
\text { bemidjiensis }\end{array}$ & $1 e-63$ & 122/206 (59\%) & \\
\hline LHK_02427 & & methyl-accepting chemotaxis protein & C. violaceum & $6 e-110$ & $227 / 629(36 \%)$ & $\mathrm{CC}$ \\
\hline LHK_02428 & & Hypothetical protein & No & & & CC \\
\hline LHK_02429 & chev4 & response regulator receiver modulated $\mathrm{CheW}$ protein & L. nitroferrum & $2 e-145$ & 248/313 (79\%) & CC \\
\hline LHK_02430 & chev5 & chemotaxis protein $\mathrm{CheV}$ & C. violaceum & $3 e-137$ & $237 / 314(75 \%)$ & CC \\
\hline LHK_02431 & cher4 & chemotaxis regulator protein $\mathrm{CheY}$ & C. violaceum & $2 e-58$ & 105/127 (82\%) & $\mathrm{CC}$ \\
\hline LHK_02432 & chez2 & chemotaxis phosphatase, CheZ & L. nitroferrum & $2 e-63$ & $129 / 248(52 \%)$ & $\mathrm{CC}$ \\
\hline
\end{tabular}


Table 4 CDSs related to chemotaxis in L. hongkongensis genome (Continued)

\begin{tabular}{|c|c|c|c|c|c|}
\hline LHK_02433 & cheA3 & CheA signal transduction histidine kinase & L. nitroferrum & 0 & $420 / 611(68 \%) \quad$ CC \\
\hline LHK_02455 & & methyl-accepting chemotaxis sensory transducer & $\begin{array}{l}\text { Candidatus } \\
\text { Accumulibacter } \\
\text { phosphates }\end{array}$ & $1 e-74$ & $154 / 326(47 \%)$ \\
\hline LHK_02575 & & putative Methyl-accepting or sensory transducer chemotaxis protein & $\begin{array}{l}\text { Alteromonadales } \\
\text { bacterium }\end{array}$ & $1 e-83$ & $172 / 407(42 \%)$ \\
\hline LHK_02814 & aer3 & chemotaxis sensory transducer & $\begin{array}{l}\text { Rhodopseudomonas } \\
\text { palustris }\end{array}$ & $8 e-42$ & $138 / 425(32 \%)$ \\
\hline LHK_02834 & & methyl-accepting chemotaxis protein & $\begin{array}{l}\text { Pseudomonas } \\
\text { syringae }\end{array}$ & $1 e-45$ & $148 / 437(33 \%)$ \\
\hline LHK_03026 & & methyl-accepting chemotaxis protein & C. violaceum & $6 e-145$ & $275 / 627(43 \%)$ \\
\hline LHK_03119 & & methyl-accepting chemotaxis sensory transducer & L. nitroferrum & $2 \mathrm{e}-133$ & $273 / 514(53 \%)$ \\
\hline LHK_03163 & & methyl-accepting chemotaxis sensory transducer & $\begin{array}{l}\text { Candidatus } \\
\text { Accumulibacter } \\
\text { phosphatis }\end{array}$ & $9 e-50$ & $167 / 494(33 \%)$ \\
\hline
\end{tabular}

${ }^{a}$ The Che proteins were encoded in three gene clusters, named CA, CB and CC (chemotaxis $A, B$ and $C$ clusters)

achromobacter secretion (PAS) domain was found in four MCPs (LHK_00564, LHK_00726, LHK_02158 and LHK_02814). PAS domains are energy-sensing modules that are found in proteins from archaea to humans [43]. The histidine kinase adenylyl cyclase MCP and phosphatase (HAMP) domain was present in 22 of the 29 MCPs. The HAMP domain interacts with the PAS domain for signal transduction in aerotaxis (oxygen-sensing) receptor in Escherichia coli [43], and possesses roles of regulating the phosphorylation or methylation of homodimeric receptors by transmitting the conformational changes in periplasmic ligand-binding domains to cytoplasmic signaling kinase and methyl-acceptor domains [44].

These chemosensory transducer proteins work as twocomponent regulatory systems which typically consist of a sensory histidine kinase and a response regulator. The histidine kinase is usually a transmembrane receptor and the response regulator a cytoplasmic protein [45]. Following autophosphorylation at a conserved histidine residue in response to changes in chemoreceptor occupancy, the histidine kinase serves as a phospho-donor for the response regulator. Once phosphorylated, the response regulator mediates changes in gene expression or cell motility. CheA is a typical sensory histidine kinase while CheY is a downstream regulator protein [46]. Upon phosphorylation, CheY binds to the FliM component at the base of the flagellar motor switch to induce clockwise rotation [47]. In contrast to the single copies of CheA and CheY in E. coli, the presence of 22 chemosensory transducer proteins, many with multiple copies including three CheA, one CheB, one CheD, two CheR, five CheV, one CheW, four CheY, and two CheZ, suggested that L. hongkongensis may utilize a complex transducer system to mediate chemotaxis response and adapt to environmental changes (Table 4). These Che proteins were encoded in three gene clusters, named CA, CB and CC. The first and largest cluster, CA, encoded two CheA, one
Cher, two CheY, two CheV, one CheZ, and the single CheD and CheW. The second and smallest cluster, CB, encoded one CheV and CheY. The third cluster, CC, encoded one CheA, one CheY, two $\mathrm{CheV}$ and one CheZ. Phylogenetic analysis of CheAs, CheVs and CheYs of $L$. hongkongensis suggested that the multiple copies are the result of both horizontal transfer events and gene duplication, as some of the copies were more closely related to the corresponding proteins in other bacteria while others were more closely related among the homologues of $L$. hongkongensis (Figure 3).

The CheA proteins of L. hongkongensis were most closely related to homologues in the closely related Chromobacterium violaceum and Lutiella nitroferrum with $47 \%$ to $72 \%$ amino acid identities. CheA has five domains, P1 to P5 [46]. All the three CheA proteins in L. hongkongensis contained these conserved domains. In the P1 domain, the invariant histidine residue, which undergoes phosphorylation by the P4 domain, was also present. In the kinase domain $\mathrm{P} 4$, the four conserved regions designated the $\mathrm{N}, \mathrm{G} 1, \mathrm{~F}$ and $\mathrm{G} 2$ boxes were also present in the three CheAs (Figure 4).

The CheY proteins of $L$. hongkongensis were highly similar to the homologues in C. violaceum and Dechloromonas aromatica, with $70 \%$ to $83 \%$ amino acid identities. Multiple alignment of the four CheY with that of E. coli showed the presence of all five amino acid residues conserved among response regulators [46,48]: aspartate at positions 12,13 and 57 ; threonine at position 87 , and lysine at position 109 , with the aspartate at position 57 representing the phosphorylation site (Figure 5). Residues that interact with P2 domain of CheA were identified.

Other Che proteins are believed to be involved in the regulation of bacterial chemotaxis, although the exact function of some are not fully understood. Among them, CheB is known to work in conjunction with CheR in the reversible methylation of the MCPs. CheR is a 


\section{CheA}

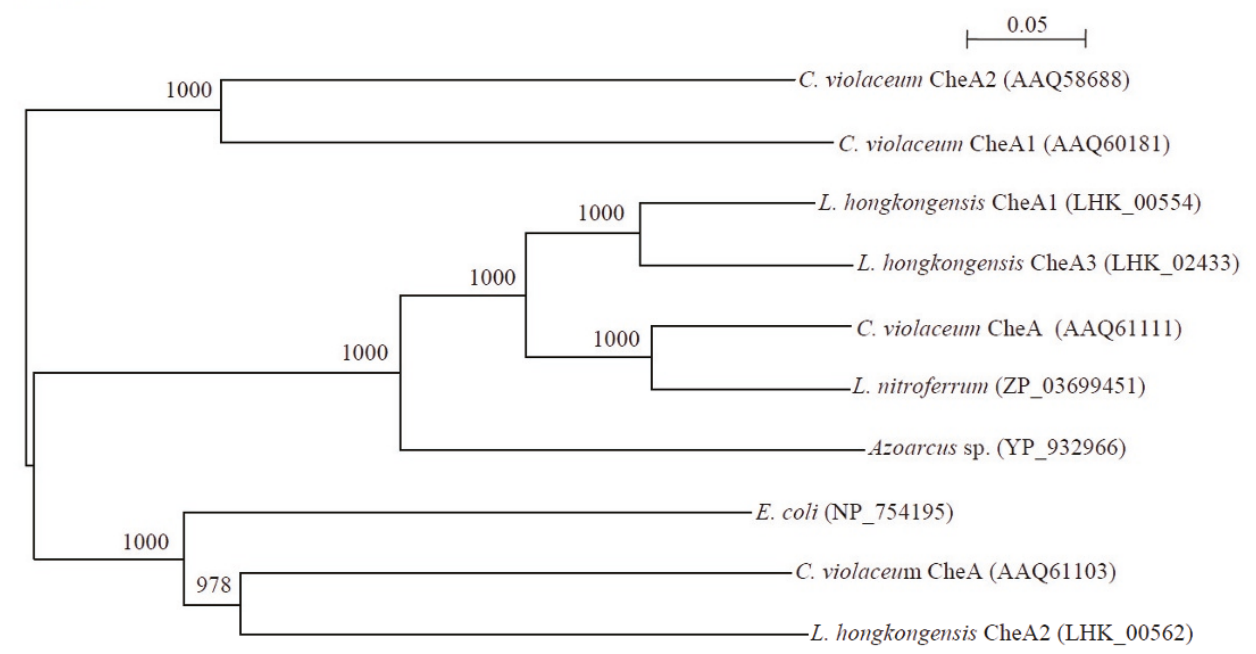

\section{$\mathrm{CheV}$}

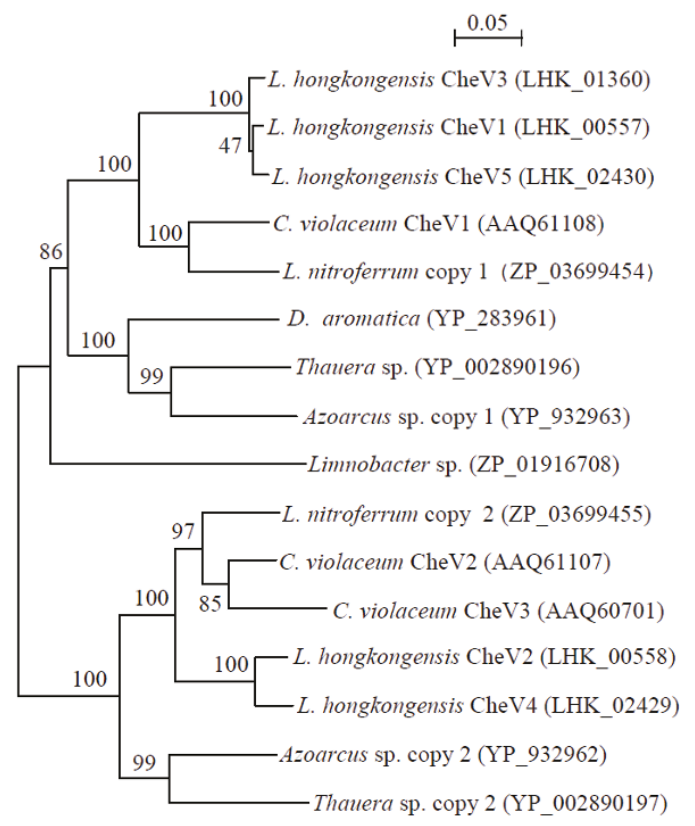

CheY

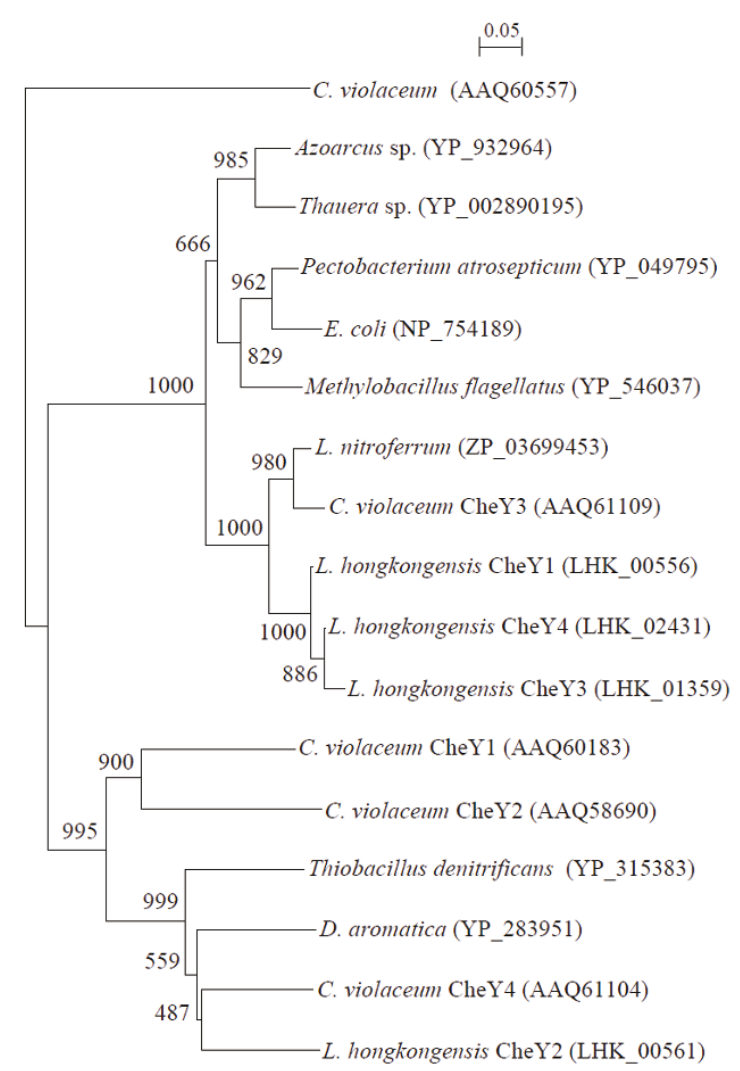

Figure 3 Phylogenetic tree showing the relationships of the CheAs, CheVs and CheYs from L. hongkongensis to those from other bacteria. The unrooted trees are constructed by using the neighbor-joining method using Kimura's two-parameter correction, with bootstrap values calculated from 1000 trees. The scale bar indicates the estimated number of substitutions per 20 bases. Bacterial names and accession numbers are given as cited in the GenBank database. 


\section{P1 domain}

Eco_cheA LHK_00554 LHK-02433

Eco_cheA
LHK_00554 LHK-00562 LHK 02433

Eco cheA

LHK-00554 LHK 00562 LHK-02433

Ecomea LHK- 00554 LHK 00562 LHK-02433

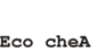

LHK 00554 LHK 00562

LHK_02433

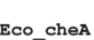

LHK- 00554 LHK 00562

LHK_02433

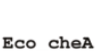

LHK 00554 LHK 00562

LHK_02433

co cheA LHK 00554 LHK 00562 LHK_02433

Eco_cheA
LHK_00554
LHK_00562
LHK_02433

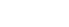

Eco cheA LHK_00554 LHK 00562 LHK_02433

Eco_cheA LHK_00554 LHK_00562 HKK 02433

Eco_cheA LHK_00554 LHK_00562 LHK 02433

MHHRSVFPQC HQPNRGDSVS MDISDFYQTF FDEADELLAD MEQHLLVLQP -EAPDAEQLN UTS -OMS IDISQFHAFF FDEAAEHLET TERLILESQP GQTTDGEATN - - - - MSDF NGMEELIODF ITESSELISD VDNKIVEIEK - YPEDKGLNN

\section{P1 domain}

AIFRAAHSTK GGAGTEGESV IOETTHIMEN LIDFARRGEM OINTDITILE IETKDIMOEO DIFRGEHTTK GGAGFLNATP LVTLCHRTEN LFDKLRNGEL KLNSHVMDVI IDATGVVRDM AIFRAAHSIK GSAGTFGEAD IAGETHGLEN LLDRIRRGEL PLTAGRISVC LKSRDVIADQ DIFRGEHTIK GGAGFLNATP IVTICHRTEN IFDKLRNGEI OTNSHUMVVI LOATGVVDM

\section{P1 domain \\ LDAYKQ-SQE PDAASFNYIC QALRQLALEA KGETPSAVTR LS------VVA KSEPQDEQSR} FGDLAQSRMP APAP----1 - LAAHRDGATA VDPGRLAEIE AALLAAHDEG T-DMPVPVTS SRPDGGHYLL CWDRQLGHP

P2 domain

SOSPRRIILS RLKAGEVDLL EEELGHLTTL TDVVKGADSL SAILP----- -DDIAEDDIT

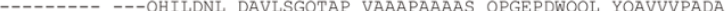
GLQDRLAALG TVQP-CGEQG EELVFOLQSG LSATDIAESL AFWLPPGOFR LEHLESQGDE --------- ---OHTLDNI DAMIAGQDMV RTVPGLPAVP DP-------- -ASVSQPASA

\section{P2 domain}

AVLCEVIEAD QITEETVD-- ---------- VSPKISTPPM LKLAAEQAPT GRVEREKTTR AAQLTSKSAP STAVAAAP-- AFGVFVDTQR VVATSATEPA APVDEGWGLF APPAAATADV SPPVAEPAAT GSTPALRQAT PP-----AAS TVAVQAGP-- ---------- -----ATTAA AQPPE----- ---RERNISG

\section{P3 domain}

SSESTSTRVA VEKVDQLINL VGELVITQSM LAQR-----S SELDPVNHGD LITSMGQLQR SPQEATIRID TQRLDQVLNL SGEIGLTKNR LTTIRTEIMQ GNLGANTLRS LDEAVSOLDI PQPETSIRVN VEKVDQLLNR IGELVITQSM LAQQ------V ERLGTLASEE LORGMAOIER NQQETTLRVD AQRLDQVLNL SGEIGLTKNR LTTIRTEIIQ GNLGADVLHS LDEAVSQLDI

\section{P3 domain \\ P4 domain}

PI LVGDLONAVM KTRMOPIGRL FQKYPRLARD LARQLGKEVE LVLSGEETEL DKTMIEDLND LTRELQEAVM SVRMLPVASV FGRFPRLVRE LGQKLGKAVE LQVIGEQTEI DKSFVEKLTD LVGDLQNAVM KTRMQPIGRL FQKYPRLARD LARQLGKDVD LVLSGEETEL DKTMIEDLND
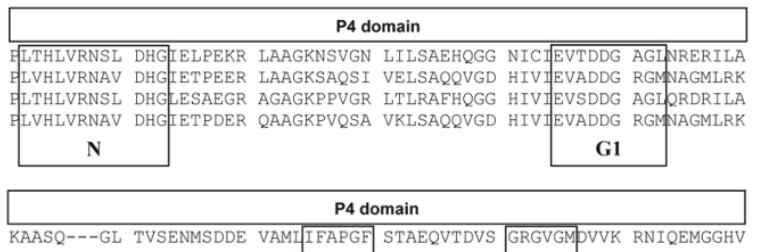
KAASQ---GL TVSENMSDDE VAMI IFAPGF STAEQVTDVS GRGVGMVVK RNIQEMGGHV GISTH KALEKGLIDL EQANSMDDKQ ALHIIFLPGF TTKSEISSVS GRGVGMPVVR TNIQKLNGRI G2

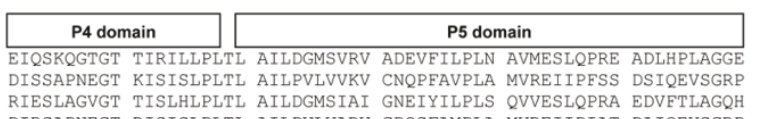
DIRSAPUETT RISISLPLTL AILPGISIARV GNEIYILPLS QV

\section{P5 domain}

RVLEVRGEYL PIVELWKVFN VAGAKTEATQ GIVVILQSGG RRYALLVDQL IGQHQVVVKN -TIVVRDEIL PVRRLTELLG WKATQEPCFG ---VLMQSAE KTFILAIDSF IGRDDVVIKP RLLRVRGECL PLLALWEIFD IQPRVREAHE GLVIIITVAS QRVALLVDDL VSQQQFVVKN

\section{P5 domain \\ LESNYRKVPG ISAATILGDG SVALIVDVSA LQAINREQRM ANTAA----- -----} LQN--IRPKG VAGATLSGDG AVVLVLDMED LLSNDRGDHK LARAGNMPML EAAAV LEN--VSIKG VAGATISGDG AVVLVIDMDS LINTDK--AH AAVHGALTPL PA--- 580

Figure 4 Amino acid sequence alignments of $\boldsymbol{L}$. hongkongensis and $\boldsymbol{E}$. coli CheAs. The conserved P1 to P5 domains are marked above the sequences. The histidine residue at potential phosphorylation site is shaded. The four conserved regions designated the N, G1, F and G2 boxes within P4 domain are marked in open boxes.

constitutively active methyltransferase which methylates the conserved glutamine residues of MCPs, while the methylesterase CheB is responsible for demethylation $[49,50]$. Similar to CheY, the CheB of L. hongkongensis also contained the five conserved amino residues of response regulators. In addition, three conserved residues of the catalytic site, serine at position 164, histidine at position 190 and aspartate at position 286 , and the 


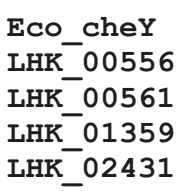

Eco_cheY

LHK 00556

LHK 00561

LHK 01359

LHK_02431
---MADKELK FLVVDDFSTM RRIVRNLLKE LGFNNVEEAE DGLDALNKLQ AGGYGFVISD MIEAADKNLR FLVVDDFSTM RRILRNLLKE LGFTNVDEAE DGQVALHKLR SQPYEFVVSD -----MAKC ILAVDDSPSI RQMVTFTLKN AGYD-IISAP DGLAGLKEAN SHRVDLVLTD MLDEVNPNLR FLVVDDFSTM RRILRNLFKE LHFTNIDEAE DGQVALHKLR SQPYEFVVSD MLDEVNPNLR FLVVDDFSTM RRILRNLLKE LHFTNIDEAE DGQVALHKLR SQPYEFVVSD

\section{$\Delta \Delta \quad \Delta \Lambda \quad \Delta \Lambda \quad \Delta \Delta \Lambda \Delta$}

WNMPNMDGLE LLKTIRADGA MSALPVLMV WNMPNMTGIE LLRAVRADAQ LRHLPFLMI QNMPGMDGLT LIRELRQLPA YRATPILMLT WNMPNMTGIE LLRAVRADAQ LRHLPFLMI WNMPNMTGIE LLRAVRADAQ LRHLPFLMIT AEAKKENIIA AAQAGASGYV VKPFTAATLE AEAKRENIIE AAQAGASGYI VKPFTAATLE TEAGDDMKAQ GRAAGASGWM VKPFDPQKLV AEAKRENIIE AAQAGASGYI VKPFTVVTLE AEAKRENIIE AAQAGASGYI VKPFTAATLE
57

60

53

60

60

$\begin{array}{lll}\text { Eco_cheY } & \text { EKLNKIFEKL GM--- } & 129 \\ \text { LHK_00556 } & \text { EKLAKIFQST SRQAG } & 135 \\ \text { LHK_00561 } & \text { DVVRKLLG-- ----- } & 121 \\ \text { LHK_01359 } & \text { EKLAKIFQST SRQAG } & 135 \\ \text { LHK_02431 } & \text { EKLAKIFQST SRQAG } & 135\end{array}$

Figure 5 Amino acid sequence alignments of $L$. hongkongensis and $E$. coli CheYs. The conserved aspartate, threonine and lysine residues are shaded. The aspirate residue at potential phosphorylation site is marked by black square, and residues of $E$. coli CheY that interact with the P2 domain of $E$. coli Che $A$ are marked by black triangles above the residues.

GXGXXG nucleotide-binding-fold sequences conserved among CheB proteins were also present (Figure 6) [51].

Similar multiple copies of chemosensory transducer proteins have also been reported in C. violaceum and Rhodobacter sphaeroides $[46,48]$. Interestingly, the organization of the first cluster in $L$. hongkongensis, CA, was similar to one of the three clusters, cluster 3 , in $C$. violaceum, although some of the genes were in opposite coding direction. In $R$. sphaeroides, it has been shown that some of the multiple copies of Che proteins are essential (e.g. CheA2) while others are not (e.g. CheA1) although the multiple chemosensory protein homologues are not redundant [46,52]. Further studies are required to investigate the differential function of the
Eco_cheB MSK-IRVLSV DDSALMRQIM TEIINSHSDM EMVATAPDPL VARDLIKKFN PDVLTLDVEM LHK_00566 MSQPVRVLVV DDSALMRNLL AELINACDGM CCVGQAADPL QARESIRLLA PDVVTLDVEM

Eco cheB PRMDGLDFLE KLMRLRPMPV VMVSSLTGKG SEVTLRALEL GAIDFVTKPQ LGIREGMLAY LHK_00566 PHMDGLEFLR RLMRLRPTPV VMVSSLTARG SEVAIEALAL GAVEVVEKPG AGLGQAIPRF

$\triangle$

Eco_cheB LHK_00566

SEMIAEKVRT AAKASLAAHK PLSAPTTLKA GPLLSSEKLI AIGASTGGTE AIRHVLQPLP AMQLTGAIQK AAQANLSRIC NLNKSPAMPS LRPPARDALV LIGASTGGTE ALVTLLSALP

$\triangle$

Eco cheB LSSPALLITQ HMPPGFTRSF ADRLNKLCQI GVKEAEDGER VLPGHAYIAP GDRHMELARS LHK_00566 AQMPPVLIVQ HMPAGFTASF ARRLDQACVL QVREAQGGEK LAPGQVWVAP GHAHLQLSAQ

Eco_cheB LHK- 00566

GANYQIKIHD GPAVNRHRPS VDVLFHSVAK QAGRNAVGVI LT GMGNDGAA GMLAMRQAGA AGDWRTQLVD SDPVNRHRPS VDVLFHSALK VAGRHTVAVL LTGMGRDGAQ GLLALRKAGA GXGXXG

Eco cheB

WTLAQNEASC VVFGMPREAI NMGGVCEVVD LSQVSQQMLA KISAGQAIRI --------YTYAQDKASS VVFGMPREAI EIGAACEVAS LGDMAHQMVT RMAGGAGGRA EEGKGVAAPH
59 60

119 120

179 180

Figure 6 Amino acid sequence alignment of L. hongkongensis and E. coli CheBs. The 5 conserved aspartate, threonine and lysine residues also found in CheY are shaded. The three conserved residues of the catalytic site Ser164, His190 and Asp286 in E. coli CheB are marked by triangles above the residues and the GXGXXG nucleotide-binding-fold consensus sequences of other CheB marked in open box. 
multiple copies of chemosensory transducer proteins in L. hongkongensis.

Flagellar proteins in L. hongkongensis

A total of 40 CDSs, arranged in six gene clusters, were likely involved in the biosynthesis of flagella in L. hongkongensis (Table 5). These six clusters, FA, FB, FC, FD,
FE and FF, encoded 11, 3, 5, 2, 16 and 3 genes respectively. The organization and gene contents of the first five clusters were highly similar to five of the seven clusters of flagellar genes (clusters 1, 2, 4, 5 and 7) previously found in C. violaceum [48], which is also a motile bacterium found in multiple ecosystems, including water and

Table 5 CDSs involved in flagella biosynthesis in L. hongkongensis genome

\begin{tabular}{|c|c|c|c|c|c|c|}
\hline CDS & Gene & Product & $\begin{array}{l}\text { Organism with the } \\
\text { closest matching } \\
\text { sequences }\end{array}$ & E-value & Identities & Cluster $^{a}$ \\
\hline LHK_00436 & $f l g L$ & flagellar hook-associated protein 3 & L. nitroferrum & $1 e-59$ & $127 / 312(40 \%)$ & FA \\
\hline LHK_00437 & flgK & flagellar hook-associated protein FlgK & L. nitroferrum & $1 e-109$ & $258 / 634(40 \%)$ & FA \\
\hline LHK_00438 & flg」 & flagellar rod assembly protein/muramidase FlgJ & L. nitroferrum & $3 e-68$ & $144 / 296(48 \%)$ & FA \\
\hline LHK_00439 & flgl & flagellar basal body P-ring protein & C. violaceum & $1 e-95$ & 197/294 (67\%) & FA \\
\hline LHK_00440 & $\mathrm{flgH}$ & flagellar L-ring protein & L. nitroferrum & $4 e-60$ & 122/231 (52\%) & FA \\
\hline LHK_00441 & $f l g G$ & flagellar basal-body rod protein FlgG & Ralstonia pickettii & $2 e-92$ & $162 / 260(62 \%)$ & FA \\
\hline LHK_00442 & flgF & flagellar basal-body rod protein FlgF & L. nitroferrum & $1 e-75$ & $143 / 246(58 \%)$ & FA \\
\hline LHK_00443 & flgE & flagellar basal body FlaE domain-containing protein & Pseudomonas putida & $4 \mathrm{e}-76$ & $212 / 598(35 \%)$ & FA \\
\hline LHK_00444 & $f l g D$ & flagellar hook capping protein & L. nitroferrum & $8 e-38$ & $88 / 240(36 \%)$ & FA \\
\hline LHK_00445 & flgC & flagellar basal-body rod protein flgC & C. violaceum & $2 \mathrm{e}-49$ & $92 / 136(67 \%)$ & FA \\
\hline LHK_00446 & $f \lg B$ & flagellar basal-body rod protein FlgB & L. nitroferrum & $2 e-41$ & $89 / 136(65 \%)$ & FA \\
\hline LHK_00584 & $f l g N$ & FlgN family protein & C. violaceum & $2 e-15$ & 48/131 (36\%) & $\mathrm{FB}$ \\
\hline LHK_00585 & $f l g M$ & anti-sigma-28 factor, FlgM & L. nitroferrum & 4e-09 & $36 / 59(61 \%)$ & $F B$ \\
\hline LHK_00586 & $f \lg A$ & flagella basal body P-ring formation protein FlgA & L. nitroferrum & $2 e-36$ & $85 / 206(41 \%)$ & $\mathrm{FB}$ \\
\hline LHK_00781 & fliA & RNA polymerase sigma factor for flagellar operon & C. violaceum & $5 e-89$ & $165 / 242(68 \%)$ & FC \\
\hline LHK_00782 & fleN & flagellar synthesis regulator FleN & L. nitroferrum & $3 e-49$ & $121 / 268(45 \%)$ & FC \\
\hline LHK_00783 & flhF & flagellar biosynthesis regulator FlhF & C. violaceum & $1 e-119$ & 250/504 (49\%) & FC \\
\hline LHK_00784 & flhA & flagellar biosynthesis protein FlhA & L. nitroferrum & 0 & $519 / 682(76 \%)$ & FC \\
\hline LHK_00785 & $f l h B$ & flagellar biosynthetic protein FlhB & L. nitroferrum & $2 e-136$ & 226/378 (59\%) & FC \\
\hline LHK_02206 & $\operatorname{mot} B$ & OmpA/MotB domain protein & L. nitroferrum & $6 e-111$ & 206/273 (75\%) & $\mathrm{FD}$ \\
\hline LHK_02207 & motA & flagellar motor protein MotA & L. nitroferrum & $9 e-123$ & $213 / 286(74 \%)$ & $\mathrm{FD}$ \\
\hline LHK_02348 & fliR & flagellar biosynthetic protein FliR & L. nitroferrum & $1 e-60$ & $142 / 258(55 \%)$ & FE \\
\hline LHK_02349 & fliQ & flagellar biosynthetic protein FliQ & L. nitroferrum & $6 e-24$ & 65/89 (73\%) & FE \\
\hline LHK_02350 & & GCN5-related N-acetyltransferase & Methylocella silvestris & $5 e-09$ & $47 / 150(31 \%)$ & FE \\
\hline LHK_02351 & flip & flagellar biosynthesis protein FliP & C. violaceum & $7 e-95$ & 178/252 (70\%) & $\mathrm{FE}$ \\
\hline LHK_02352 & fliO & flagellar protein FliO & C. violaceum & $2 e-16$ & $52 / 100(52 \%)$ & FE \\
\hline LHK_02353 & fliN & flagellar motor switch protein FliN & L. nitroferrum & $2 e-54$ & $111 / 140(79 \%)$ & FE \\
\hline LHK_02354 & flim & flagellar motor switch protein FliM & L. nitroferrum & $3 e-160$ & 272/327 (83\%) & $\mathrm{FE}$ \\
\hline LHK_02355 & flil & flagellar fliL transmembrane protein & C. violaceum & $2 e-28$ & $64 / 136(47 \%)$ & $\mathrm{FE}$ \\
\hline LHK_02356 & flik & flagellar hook-length control protein & $\begin{array}{l}\text { Nitrosomonas } \\
\text { europaea }\end{array}$ & $5 e-18$ & $41 / 108(37 \%)$ & $\mathrm{FE}$ \\
\hline LHK_02357 & flij & flagellar export protein FliJ & L. nitroferrum & $3 e-20$ & $64 / 142(45 \%)$ & FE \\
\hline LHK_02358 & flil & flagellar protein export ATPase Flil & L. nitroferrum & 0 & $331 / 453(73 \%)$ & $\mathrm{FE}$ \\
\hline LHK_02359 & $\mathrm{fliH}$ & flagellar assembly protein FliH & L. nitroferrum & $8 e-32$ & 109/275 (39\%) & $\mathrm{FE}$ \\
\hline LHK_02360 & fliG & flagellar motor switch protein FliG & L. nitroferrum & $2 e-148$ & 261/332 (78\%) & FE \\
\hline LHK_02361 & fliF & flagellar M-ring protein FliF & L. nitroferrum & 0 & $339 / 585(57 \%)$ & FE \\
\hline LHK_02362 & fliE & flagellar hook-basal body complex subunit FliE & L. nitroferrum & $5 e-27$ & $69 / 110(62 \%)$ & FE \\
\hline LHK_02363 & & two component, sigma54 specific, transcriptional regulator, Fis family & L. nitroferrum & $2 e-143$ & $279 / 450(62 \%)$ & FE \\
\hline LHK_02703 & fliD & flagellar hook-associated 2 domain protein & L. nitroferrum & $5 e-45$ & 136/445 (30\%) & FF \\
\hline LHK_02704 & flaG & FlaG flagellar protein & $\begin{array}{l}\text { Janthinobacterium } \\
\text { sp. Marseille }\end{array}$ & $2 \mathrm{e}-11$ & $38 / 105(36 \%)$ & $\mathrm{FF}$ \\
\hline LHK_02705 & flic & flagellin domain-containing protein & Acidovorax sp. & $2 \mathrm{e}-73$ & $159 / 288(55 \%)$ & FF \\
\hline
\end{tabular}

${ }^{a}$ The flagellar proteins were arranged in six gene clusters, $F A, F B, F C, F D, F E$ and $F F$ (flagellar $A, B, C, D, E$ and $F$ clusters) 
soil. On the other hand, the pathogenic Neisseria species, Neisseria gonorrhoeae and Neisseria meningitides, which also belong to the same Neisseriaceae family, are nonmotile with humans being the only host and reservoir, and do not possess flagellar genes.

A bacterial flagellum is typically composed of three parts, the filament formed by flagellin subunits, basal body attached to the bacterial cell membrane, and the hook which links between the filament and basal body [53]. All the major proteins that form these flagellar components were present in the L. hongkongensis genome. They included FliC and FliD which form the major part of the filament; FlgE, FlgK and FlgL which form the hook and hook-filament junction; and $\mathrm{Flg} \mathrm{B}$, FlgC, FlgH, FlgI, FlhA, FlhB, FliF, FliG, FliH, FliI, FliM, FliN, FliO, FliP, FliQ, FliR, MotA and MotB which form the basal body and flagellar-motor complex. Putative regulators of these flagellar proteins were also identified. FlgD and FliK are regulators of the hook component FlgE. FlgA, FlgN (both being chaperon proteins) and FliJ are involved in export of flagellar components. The anti-sigma factor gene FlgM and $\sigma 28 \mathrm{FliA}$ that regulates late gene products were also present. However, similar to C. violaceum, the L. hongkongensis genome lacked the FlhDC operon genes, suggesting that the regulation of flagellar protein expression is controlled by FlgM/FliA in this group of bacteria.

\section{Quorum sensing in L. hongkongensis}

In addition to chemotaxis through which bacteria can rapidly adapt to environmental changes, quorum sensing is another way to assess the environment and to recognize the host. Quorum sensing is a signaling system through which bacteria can communicate among themselves by the production of and response to chemical signals called autoinducers [54]. In response to the changing concentrations of these autoinducers, downstream gene expression can be regulated. This cell-to-cell communication system, first identified in Vibrio harveyi in the regulation of bioluminescence, is now known to exist in diverse bacteria, especially those that reside in the gastrointestinal tract where recognition of the host may be important for survival and virulence gene expression [54,55]. Among the three major quorum-sensing mechanisms, including the LuxR-I, LuxS/AI-2, and AI-3/epinephrine/norepinephrine systems, known to be utilized by enteric bacteria, only the latter was found in the L. hongkongensis genome, suggesting that this system played a major role in quorum-sensing in the bacterium [14].

The AI-3/epinephrine/norepinephrine system is involved in inter-kingdom cross-signaling and regulation of virulence gene transcription and motility [54]. This mechanism is best characterized in enterohemorrhagic E. coli (EHEC) which causes fatal hemorrhagic colitis and hemolytic uremic syndrome. It has been shown that the locus of enterocyte effacement (LEE), an important virulence factor in EHEC, and the flagellar genes of EHEC are regulated by the AI-3 system which involves AI-3 produced by the commensal gastrointestinal microflora and/or epinephrine/norepinephrine produced by the host $[56,57]$. The AI-3 system has also been implicated in biofilm formation in enteropathogenic E. coli (EPEC) [58]. Clarke et al. have recently identified the protein, QseC that binds to AI-3 and epinephrine/norepinephrine, suggesting its involvement in the AI-3 system [59]. QseC belongs to a two-component system, QseB/C, in which QseC is the sensor kinase and QseB the response regulator. $\mathrm{QseB} / \mathrm{C}$ has also been shown to be involved in activation of the flagella regulon and virulence in a rabbit model for EHEC $[59,60]$. The L. hongkongensis genome contained two sets of genes, LHK_00329/LHK_00328 and LHK_1812/LHK_1813, homologous to qseB/qseC [14], most closely related to homologues in C. violaceum and Azoarcus sp. strain BH72 respectively. The two qseB genes in L. hongkongensis possessed the response regulator receiver domain (PF00072) and the C-terminal domain of transcriptional regulatory protein (PF00486) previously found in the QseB of E. coli. The two qseC genes in L. hongkongensis also contained the His Kinase A (phosphoacceptor) domain (PF00512) and the histidine kinase-, DNA gyrase B-, and HSP90-like ATPase domain (PF02518) previously identified in the QseC of E. coli. The presence of two copies of qseB/qseC suggested that the AI-3 system may be an important mechanism for adaptation to the changing environment and animal hosts for $L$. hongkongensis.

\section{Conclusions}

A large number of diverse transporters $(n=457)$, including those from all seven major transporter categories, were identified in the L. hongkongensis genome. A diversity of genes involved in chemotaxis, motility and quorum sensing were also found. This suggested that the ability to transport various substances plays an important role in the physiology or survival of L. hongkongensis, which may also utilize a complex system to mediate chemotaxis response and adapt to and survive in the rapidly changing environments. In particular, the bacterium is unique among closely related members of Neisseriaceae family in possessing higher number of proteins related to transport of ammonium, urea and dicarboxylate, which may reflect the importance of nitrogen and dicarboxylate metabolism in L. hongkogensis which is assacharolytic. Structural modeling of two $\mathrm{C}_{4}$-dicarboxylate transporters showed that they possessed similar structures to the determined structures of other DctP-TRAP transporters, but one with a rarely seen disulfide bond. A large number of $A B C$ transporters were also identified. These suggest that the bacterium may be able to transport a wide variety of substrates including antibiotics, dyes, detergents, 
fatty acids, bile salts, organic solvents, ions, amino acids, drugs, heavy metals such as nickel and cobalt, nucleobase, $\mathrm{C}_{4}$-dicarboxylates and other metabolites. Diverse mechanisms for iron transport, including hemin transporters for iron acquisition from host proteins, were identified, suggesting that the bacterium may adapt to iron limitation present in human host. Using blastp of all transporters against rcsb pdb, many of these genes were also found to have homolgous proteins of high sequence identities with known structures (data not shown). The large number of chemosensory transducer proteins, many having multiple copies arisen from both horizontal transfer events and gene duplications, may constitute a complex transducer system for mediating chemotaxis response and adapt to environmental changes. The presence of two copies of qseB/qseC homologs suggests that L. hongkongensis may use the AI-3 system for cross-kingdom quorum-sensing and regulation of potential virulence factors. Further studies are required to better characterize the precise target substance for transport proteins of interest, and the targets regulated by qseB/ $q s e C$ in L. hongkongensis, which may shed light on its potential mechanisms for pathogenicity. Structural modeling can be a useful tool to provide useful structural insights about these genes in L. hongkongensis.

\section{Methods}

Transport genes were identified and classified according to Transport Classification Database TCDB http://www. tcdb.org/ and manual annotation. These CDSs were from COG C (Energy production and conversion), COG D (Cell cycle control, cell division, chromosome partitioning), COG E (Amino acid transport and metabolism), COG F (Nucleotide transport and metabolism), COG G (Carbohydrate transport and metabolism), COG $\mathrm{H}$ (Coenzyme transport and metabolism), COG I (Lipid transport and metabolism), COG J (Translation, ribosomal structure and biogenesis), COG K (Transcription), COG L (Replication, recombination and repair), COG M (Cell wall/membrane/envelope biogenesis), COG N (Cell motility), COG O (post-translational modification, protein turnover, chaperones), COG P (Inorganic ion transport and metabolism), COG Q (Secondary metabolites biosynthesis, transport and catabolism), COG R (General function prediction only), COG S (Function unknown), COG T (Signal transduction mechanisms), COG U (Intracellular trafficking, secretion and vesicular transport) and COG V (Defense mechanisms). CDSs that were classified to COG N (cell motility) and COG $\mathrm{T}$ (signal transduction mechanisms), and COG M (cell wall/membrane/envelope biogenesis) were manually annotated for identification of genes related to chemotaxis, motility and quorum sensing. CDSs from other COGs were searched for additional genes using keywords: chemotaxis, che, MCP, flagellar etc. All putative genes were studied by manual curation based on the BLASTx result or multiple alignments. Phylogenetic relationships were determined using Clustal $\times$ version 1.81. Protein family analysis was performed using PFAM [61]. Results were also compared to those of N. gonorrhoeae, N. meningitidis, C. violaceum, which were the other bacterial species in the Neisseriaceae family with complete genome sequences available, where appropriate $[29,62-70]$. Genes encoding TRAP transporters were located and annotated as described above. Sequence analysis for the presence of signal peptide and transmembrane domains were performed using SignalP v3.0 and TMHMM v2.0 servers respectively [71,72]. Identification of homologs in other bacteria was performed by using BLASTP sequence similarity search against the $\mathrm{nr}$ database in NCBI GenBank. The predicted sequences of mature SBPs were submitted to the I-TASSER server for homology modeling using default parameters and available structures of several DctP-type SBP homologs (PDB code: 3B50, 2XA5, 3GYY, 3FXB, 2HPG, and 2CEY) as templates [73]. If multiple homology models were returned, then the best model was selected for further analysis based on the C-score. Quality assessment of the homology model was performed using PROCHECK [74] and ProSA-web [75]. Presence and connectivity of disulfide bonds in the protein were predicted using the DiANNA v1.1 server [76]. Structural alignment of the homology models of SBPs in L. hongkongensis and related structures in Protein Data Bank (http://www. pdb.org) was performed using the MatchMaker tool of UCSF Chimera with selected structures (PDB code: 2HZK, 2CEY, 2VPN, 2PFZ, 2PFY, and 2ZZV) [77]. Molecular images were generated using UCSF Chimera.

\section{List of abbreviations}

ABC: ATP-binding cassette; ATP: Adenosine-5'-triphosphate; BFR: Bacterioferritin; CDS(s): Coding sequences(s); COG: Clusters of orthologous group; CPS-E: Capsular polysaccharide export; CrcB: Camphor resistance; DAACS: Dicarboxylate/amino acid:cation (Na or H) Symporter; DASS: Divalent Anion:Na+ Symporter; Dcu: $C_{4}$-dicarboxylate uptake; DNA: Deoxyribonucleic acid; DsbB: Disulfide bond oxidoreductase B; DsbD: Disulfide bond oxidoreductase D; EHEC: Enterohemorrhagic E. coli; EPEC: Enteropathogenic E. coli; El: Enzyme I; FAT: Fatty acid transporter; G: Guanine; HAMP: Histidine kinase adenylyl cyclase MCP and phosphatase; HCC: HlyC/CorC; LEE: Locus of enterocyte effacement; MCP(s): Methyl-accepting chemotaxis protein(s); MFP: Membrane fusion protein; MFS: Major facilitator superfamily; PAS: Plasmid achromobacter secretion; PMO: Prokaryotic molybdopterin-cont; P-P-bond: Diphosphate bond; PTS: Phosphotransferase system; RND: Resistancenodulation-cell-division; TCDB: Transport protein database; TerC: Tellurium ion resistance; TRAP-T: Tripartite ATP-independent periplasmic transporter; VISP: Putative type VI symbiosis/virulence secretory pathway.

\section{Acknowledgements}

This work is partly supported by the Research Grant Council Grant, Committee for Research and Conference Grant and University Development Fund, The University of Hong Kong; the HKSAR Research Fund for the Control of Infectious Diseases of the Health, Welfare and Food Bureau. We are grateful to support from the Genome Research Centre, The University of 
Hong Kong, and the generous support of Mrs. Carol Yu, Professor Richard Yu, Mr. Hui Hoy and Mr. Hui Ming in the genomic sequencing platform.

\section{Author details}

${ }^{1}$ State Key Laboratory of Emerging Infectious Diseases, Hong Kong. ${ }^{2}$ Research Centre of Infection and Immunology, The University of Hong Kong, Hong Kong. ${ }^{3}$ Carol Yu Centre for Infection, The University of Hong Kong, Hong Kong. ${ }^{4}$ Department of Microbiology, The University of Hong Kong, Hong Kong. 'Department of Chemistry, The University of Hong Kong, Hong Kong.

\section{Authors' contributions}

PCYW, KYY and SKPL designed and supervised the study. RYYF, GKMW and JLLT annotated the genome. HT and KHS performed bioinformatics analysis. SKPL, RYYF and GKMW drafted the manuscript. All authors read, corrected and approved the final manuscript.

\section{Competing interests}

The authors declare that they have no competing interests.

Received: 22 February 2011 Accepted: 17 August 2011

Published: 17 August 2011

\section{References}

1. Yuen KY, Woo PCY, Teng JLL, Leung KW, Wong MKM, Lau SKP: Laribacter hongkongensis gen. nov., sp. nov., a novel Gram-negative bacterium isolated from a cirrhotic patient with bacteremia and empyema. J Clin Microbiol 2001, 39:4227-4232.

2. Woo PCY, Lau SKP, Teng JLL, Yuen KY: Current status and future directions of Laribacter hongkongensis, a novel bacterium associated with gastroenteritis and traveller's diarrhoea. Curr Opin Infect Dis 2005 18:413-419.

3. Lau SKP, Woo PCY, Hui WT, Li MWS, Teng JLL, Que TL, Yung RWH, Luk WK, Lai RWM, Yuen KY: Use of cefoperazone MacConkey agar for selective isolation of Laribacter hongkongensis. J Clinl Microbiol 2003, 41:4839-4841.

4. Woo PCY, Kuhnert P, Burnens AP, Teng JLL, Lau SKP, Que TL, Yau HH, Yuen KY: Laribacter hongkongensis: a potential cause of infectious diarrhea. Diagn Microbiol Infect Dis 2003, 47:551-556.

5. Woo PCY, Lau SKP, Teng JLL, Que TL, Yung RWH, Luk WK, Lai RWM, Hui WT, Wong SSY, Yau HH, Yuen KY: Association of Laribacter hongkongensis in community-acquired gastroenteritis with travel and eating fish: a multicentre case-control study. Lancet 2004, 363:1941-1947.

6. Teng JL, Woo PC, Ma SS, Sit TH, Ng LT, Hui WT, Lau SK, Yuen KY: Ecoepidemiology of Laribacter hongkongensis, a novel bacterium associated with gastroenteritis. J Clin Microbiol 2005, 43:919-922.

7. Lau SK, Woo PC, Fan RY, Ma SS, Hui WT, Au SY, Chan LL, Chan JY, Lau AT, Leung KY, Pun TC, She HH, Wong CY, Wong LL, Yuen KY: Isolation of Laribacter hongkongensis, a novel bacterium associated with gastroenteritis, from drinking water reservoirs in Hong Kong. J Appl Microbiol 2007, 103:507-515.

8. Ni XP, Ren SH, Sun JR, Xiang HQ, Gao Y, Kong QX, Cha J, Pan JC, Yu H, Li HM: Laribacter hongkongensis isolated from a patient with communityacquired gastroenteritis in Hangzhou City. J Clin Microbiol 2007, 45:255-256.

9. Lau SK, Lee LC, Fan RY, Teng JL, Tse CW, Woo PC, Yuen KY: Isolation of Laribacter hongkongensis, a novel bacterium associated with gastroenteritis, from Chinese tiger frog. Int J Food Microbiol 2009, 129:78-82

10. Tsang N, Macnab R, Koshland DE Jr: Common mechanism for repellents and attractants in bacterial chemotaxis. Science 1973, 181:60-63.

11. Falke JJ, Bass RB, Butler SL, Chervitz SA, Danielson MA: The two-component signaling pathway of bacterial chemotaxis: a molecular view of signal transduction by receptors, kinases, and adaptation enzymes. Annu Rev Cell Dev Biol 1997, 13:457-512.

12. Blair DF: How bacteria sense and swim. Annu Rev Microbio/ 1995, 49:489-522.

13. Stock AM, Mowbray SL: Bacterial chemotaxis-a field in motion. Curr Opin Struct Biol 1995, 5:744-751.

14. Woo PC, Lau SK, Tse H, Teng J, Curreem SO, Tsang AK, Fan RY, Wong GK, Huang Y, Loman NJ, Snyder LA, Cai JJ, Huang JD, Mak W, Pallen MJ, Lok S, Yuen KY: The complete genome and proteome of Laribacter hongkongensis reveal potential mechanisms for adaptations to different temperatures and habitats. PLoS Genet 2009, 5:e1000416.

15. Jap BK, Walian PJ: Structure and functional mechanism of porins. Physio Rev 1996, 76:1073-1088.

16. Benz R, Bauer K: Permeation of hydrophilic molecules through the outer membrane of gram-negative bacteria. Review on bacterial porins. Eur $J$ Biochem 1988, 176:1-19.

17. Booth IR, Edwards MD, Black S, Schumann U, Miller S: Mechanosensitive channels in bacteria: signs of closure? Nat Rev Microbio/ 2007, 5:431-440.

18. Pao SS, Paulsen IT, Saier MH Jr: Major facilitator superfamily. Microbiol Mol Biol Rev 1998, 62:1-34.

19. Tseng T, Gratwick KS, Kollman J, Park D, Nies DH, Goffeau A, Saier MH Jr: The RND permease superfamily: an ancient, ubiquitous and diverse family that includes human disease and development proteins. $J \mathrm{Mol}$ Microbiol Biotechnol 1999, 1:107-125.

20. Blair JM, Piddock $\amalg$ : Structure, function and inhibition of RND efflux pumps in Gram-negative bacteria: an update. Curr Opin Microbiol 2009, 12:512-519.

21. Janausch IG, Zientz E, Tran QH, Kroger A, Unden G: C4-dicarboxylate carriers and sensors in bacteria. Biochim Biophys Acta 2002, 1553:39-56.

22. Dimroth $P$, Schink B: Energy conservation in the decarboxylation of dicarboxylic acids by fermenting bacteria. Arch Microbiol 1998, 170:69-77.

23. Mulligan C, Fischer M, Thomas GH: Tripartite ATP-independent periplasmic (TRAP) transporters in bacteria and archaea. FEMS Microbiol Rev 2011, 35:68-86

24. Kelly DJ, Thomas GH: The tripartite ATP-independent periplasmic (TRAP) transporters of bacteria and archaea. FEMS Microbiol Rev 2001, 25:405-424.

25. Fischer M, Zhang QY, Hubbard RE, Thomas GH: Caught in a TRAP: substrate-binding proteins in secondary transport. Trends Microbiol 2010, 18:471-478.

26. Forward JA, Behrendt MC, Wyborn NR, Cross R, Kelly DJ: TRAP transporters: a new family of periplasmic solute transport systems encoded by the dctPQM genes of Rhodobacter capsulatus and by homologs in diverse gram-negative bacteria. J Bacteriol 1997, 179:5482-5493.

27. Mulligan C, Geertsma ER, Severi E, Kelly DJ, Poolman B, Thomas GH: The substrate-binding protein imposes directionality on an electrochemical sodium gradient-driven TRAP transporter. Proc Natl Acad Sci USA 2009, 106:1778-1783.

28. Johnston JW, Coussens NP, Allen S, Houtman JC, Turner KH, Zaleski A, Ramaswamy S, Gibson BW, Apicella MA: Characterization of the $\mathrm{N}$-acetyl5-neuraminic acid-binding site of the extracytoplasmic solute receptor (SiaP) of nontypeable Haemophilus influenzae strain 2019. J Biol Chem 2008, 283:855-865

29. Grangeiro TB, Jorge DM, Bezerra WM, Vasconcelos AT, Simpson AJ: Transport genes of Chromobacterium violaceum: an overview. Genet $\mathrm{Mol}$ Res 2004, 3:117-133.

30. Kos V, Ford RC: The ATP-binding cassette family: a structural perspective. Cell Mol Life Sci 2009, 66:3111-3126.

31. Higgins CF: $A B C$ transporters: physiology, structure and mechanism-an overview. Res Microbiol 2001, 152:205-210.

32. Dimroth P: Primary sodium ion translocating enzymes. Biochim Biophys Acta 1997, 1318:11-51.

33. Barabote RD, Saier MH Jr: Comparative genomic analyses of the bacterial phosphotransferase system. Microbiol Mol Biol Rev 2005, 69:608-634.

34. Fischbach MA, Lin H, Liu DR, Walsh CT: How pathogenic bacteria evade mammalian sabotage in the battle for iron. Nat Chem Biol 2006, 2:132-138.

35. Carniel E: The Yersinia high-pathogenicity island: an iron-uptake island. Microbes Infect 2001, 3:561-569.

36. Braun V: Energy-coupled transport and signal transduction through the gram-negative outer membrane via TonB-ExbB-ExbD-dependent receptor proteins. FEMS Microbiol Rev 1995, 16:295-307.

37. Simon N, Coulanges V, Andre P, Vidon DJ: Utilization of exogenous siderophores and natural catechols by Listeria monocytogenes. Appl Environ Microbiol 1995, 61:1643-1645.

38. Wandersman C, Stojiljkovic I: Bacterial heme sources: the role of heme, hemoprotein receptors and hemophores. Curr Opin Microbiol 2000, 3:215-220

39. Cartron ML, Maddocks S, Gillingham P, Craven CJ, Andrews SC: Feotransport of ferrous iron into bacteria. Biometals 2006, 19:143-157. 
40. Harrison PM, Arosio P: The ferritins: molecular properties, iron storage function and cellular regulation. Biochim Biophys Acta 1996, 1275:161-203.

41. Gibson TJ, Koonin EV, Musco G, Pastore A, Bork P: Friedreich's ataxia protein: phylogenetic evidence for mitochondrial dysfunction. Trends Neurosci 1996, 19:465-468.

42. Cavadini P, O'Neill HA, Benada O, Isaya G: Assembly and iron-binding properties of human frataxin, the protein deficient in Friedreich ataxia. Hum Mol Genet 2002, 11:217-227.

43. Taylor BL, Zhulin IB, Johnson MS: Aerotaxis and other energy-sensing behavior in bacteria. Annu Rev Microbiol 1999, 53:103-128.

44. Aravind L, Ponting CP: The cytoplasmic helical linker domain of receptor histidine kinase and methyl-accepting proteins is common to many prokaryotic signalling proteins. FEMS Microbiol Lett 1999, 176:111-116.

45. Egger LA, Park H, Inouye M: Signal transduction via the histidyl-aspartyl phosphorelay. Genes Cells 1997, 2:167-184.

46. Porter SL, Armitage JP: Phosphotransfer in Rhodobacter sphaeroides chemotaxis. J Mol Biol 2002, 324:35-45.

47. Welch M, Oosawa K, Aizawa S, Eisenbach M: Phosphorylation-dependent binding of a signal molecule to the flagellar switch of bacteria. Proc Natl Acad Sci USA 1993, 90:8787-8791.

48. Pereira M, Parente JA, Bataus LA, Cardoso DD, Soares RB, Soares CM: Chemotaxis and flagellar genes of Chromobacterium violaceum. Genet Mol Res 2004, 3:92-101.

49. Russell CB, Stewart RC, Dahlquist FW: Control of transducer methylation levels in Escherichia coli: investigation of components essential for modulation of methylation and demethylation reactions. J Bacteriol 1989, 171:3609-3618.

50. Sherris D, Parkinson JS: Posttranslational processing of methyl-accepting chemotaxis proteins in Escherichia coli. Proc Natl Acad Sci USA 1981, 78:6051-6055

51. West AH, Martinez-Hackert E, Stock AM: Crystal structure of the catalytic domain of the chemotaxis receptor methylesterase, CheB. J Mol Biol 1995, 250:276-290

52. Porter SL, Warren AV, Martin AC, Armitage JP: The third chemotaxis locus of Rhodobacter sphaeroides is essential for chemotaxis. Mol Microbiol 2002, 46:1081-1094.

53. DePamphilis ML, Adler J: Purification of intact flagella from Escherichia coli and Bacillus subtilis. J Bacteriol 1971, 105:376-383.

54. Kendall MM, Sperandio V: Quorum sensing by enteric pathogens. Curr Opin Gastroenterol 2007, 23:10-15

55. Nealson $\mathrm{KH}$, Platt T, Hastings JW: Cellular control of the synthesis and activity of the bacterial luminescent system. J Bacteriol 1970, 104:313-322.

56. Sperandio V, Torres AG, Kaper JB: Quorum sensing Escherichia coli regulators $B$ and $C(Q s e B C)$ : a novel two-component regulatory system involved in the regulation of flagella and motility by quorum sensing in E. coli. Mol Microbiol 2002, 43:809-821.

57. Sperandio V, Mellies JL, Nguyen W, Shin S, Kaper JB: Quorum sensing controls expression of the type III secretion gene transcription and protein secretion in enterohemorrhagic and enteropathogenic Escherichia coli. Proc Natl Acad Sci USA 1999, 96:15196-15201.

58. Moreira CG, Palmer K, Whiteley M, Sircili MP, Trabulsi LR, Castro AF, Sperandio V: Bundle-forming pili and EspA are involved in biofilm formation by enteropathogenic Escherichia coli. J Bacteriol 2006, 188:3952-3961.

59. Clarke MB, Hughes DT, Zhu C, Boedeker EC, Sperandio V: The QseC sensor kinase: a bacterial adrenergic receptor. Proc Natl Acad Sci USA 2006, 103:10420-10425.

60. Clarke MB, Sperandio V: Transcriptional regulation of flhDC by QseBC and sigma FliA) in enterohaemorrhagic Escherichia coli. Mol Microbiol 2005, 57:1734-1749

61. Bateman A, Birney E, Cerruti L, Durbin R, Etwiller L, Eddy SR, GriffithsJones S, Howe KL, Marshall M, Sonnhammer EL: The Pfam protein families database. Nucleic Acids Res 2002, 30:276-280.

62. Project BNG: The complete genome sequence of Chromobacterium violaceum reveals remarkable and exploitable bacterial adaptability. Proc Natl Acad Sci 2003, 100:11660-11665.

63. Tettelin H, Saunders NJ, Heidelberg J, Jeffries AC, Nelson KE, Eisen JA, Ketchum KA, Hood DW, Peden JF, Dodson RJ, Nelson WC, Gwinn ML, DeBoy R, Peterson JD, Hickey EK, Haft DH, Salzberg SL, White O, Fleischmann RD, Dougherty BA, Mason T, Ciecko A, Parksey DS, Blair E, Cittone $\mathrm{H}$, Clark EB, Cotton MD, Utterback TR, Khouri H, Qin H, et al:
Complete genome sequence of Neisseria meningitidis serogroup B strain MC58. Science 2000, 287:1809-1815.

64. Parkhill J, Achtman M, James KD, Bentley SD, Churcher C, Klee SR, Morelli G, Basham D, Brown D, Chillingworth T, Davies RM, Davis P, Devlin K, Feltwell T, Hamlin N, Holroyd S, Jagels K, Leather S, Moule S, Mungall K, Quail MA, Rajandream MA, Rutherford KM, Simmonds M, Skelton J, Whitehead S, Spratt BG, Barrell BG: Complete DNA sequence of a serogroup A strain of Neisseria meningitidis Z2491. Nature 2000, 404:502-506.

65. Bentley SD, Vernikos GS, Snyder LA, Churcher C, Arrowsmith C, Chillingworth T, Cronin A, Davis PH, Holroyd NE, Jagels K, Maddison M, Moule S, Rabbinowitsch E, Sharp S, Unwin L, Whitehead S, Quail MA, Achtman M, Barrell B, Saunders NJ, Parkhill J: Meningococcal genetic variation mechanisms viewed through comparative analysis of serogroup C strain FAM18. PLoS Genet 2007, 3:e23.

66. Chung GT, Yoo JS, Oh HB, Lee YS, Cha SH, Kim SJ, Yoo CK: Complete genome sequence of Neisseria gonorrhoeae NCCP11945. J Bacteriol 2008, 190:6035-6036.

67. Peng J, Yang L, Yang F, Yang J, Yan Y, Nie H, Zhang $X$, Xiong Z, Jiang $Y$, Cheng F, Xu X, Chen S, Sun L, Li W, Shen Y, Shao Z, Liang X, Xu J, Jin Q: Characterization of ST-4821 complex, a unique Neisseria meningitidis clone. Genomics 2008, 91:78-87.

68. Schoen C, Blom J, Claus H, Schramm-Glück A, Brandt P, Müller T, Goesmann A, Joseph B, Konietzny S, Kurzai O, Schmitt C, Friedrich T, Linke B, Vogel U, Frosch M: Whole-genome comparison of disease and carriage strains provides insights into virulence evolution in Neisseria meningitidis. Proc Natl Acad Sci USA 2008, 105:3473-3478.

69. Rusniok C, Vallenet D, Floquet S, Ewles H, Mouzé-Soulama C, Brown D, Lajus A, Buchrieser C, Médigue C, Glaser P, Pelicic V: NeMeSys: a biological resource for narrowing the gap between sequence and function in the human pathogen Neisseria meningitidis. Genome Biol 2009, 10:R110.

70. Joseph B, Schneiker-Bekel S, Schramm-Glück A, Blom J, Claus H, Linke B, Schwarz RF, Becker A, Goesmann A, Frosch M, Schoen C: Comparative genome biology of a serogroup $B$ carriage and disease strain supports a polygenic nature of meningococcal virulence. J Bacteriol 2010, 192:5363-5377.

71. Emanuelsson O, Brunak S, von Heijne G, Nielsen H: Locating proteins in the cell using TargetP, SignalP and related tools. Nat Protoc 2007 2:953-971

72. Krogh A, Larsson B, von Heijne G, Sonnhammer EL: Predicting transmembrane protein topology with a hidden Markov model: application to complete genomes. J Mol Biol 2001, 305:567-580.

73. Roy A, Kucukural A, Zhang Y: I-TASSER: a unified platform for automated protein structure and function prediction. Nat Protoc 2010, 5:725-738.

74. Laskowski RA, MacArthur MW, Moss DS, Thornton JM: PROCHECK - a program to check the stereochemical quality of protein structures. $J$ App Cryst 1993, 26:283-291.

75. Wiederstein M, Sippl MJ: ProSA-web: interactive web service for the recognition of errors in three-dimensional structures of proteins. Nucleic Acids Res 2007, 35:W407-410

76. Ferre F, Clote P: DiANNA 1.1: an extension of the DiANNA web server for ternary cysteine classification. Nucleic Acids Res 2006, 34:W182-185.

77. Pettersen EF, Goddard TD, Huang CC, Couch GS, Greenblatt DM, Meng EC, Ferrin TE: UCSF Chimera-a visualization system for exploratory research and analysis. J Comput Chem 2004, 25:1605-1612.

doi:10.1186/2045-3701-1-28

Cite this article as: Lau et al.: Transport genes and chemotaxis in Laribacter hongkongensis: a genome-wide analysis. Cell \& Bioscience 2011 $1: 28$. 